
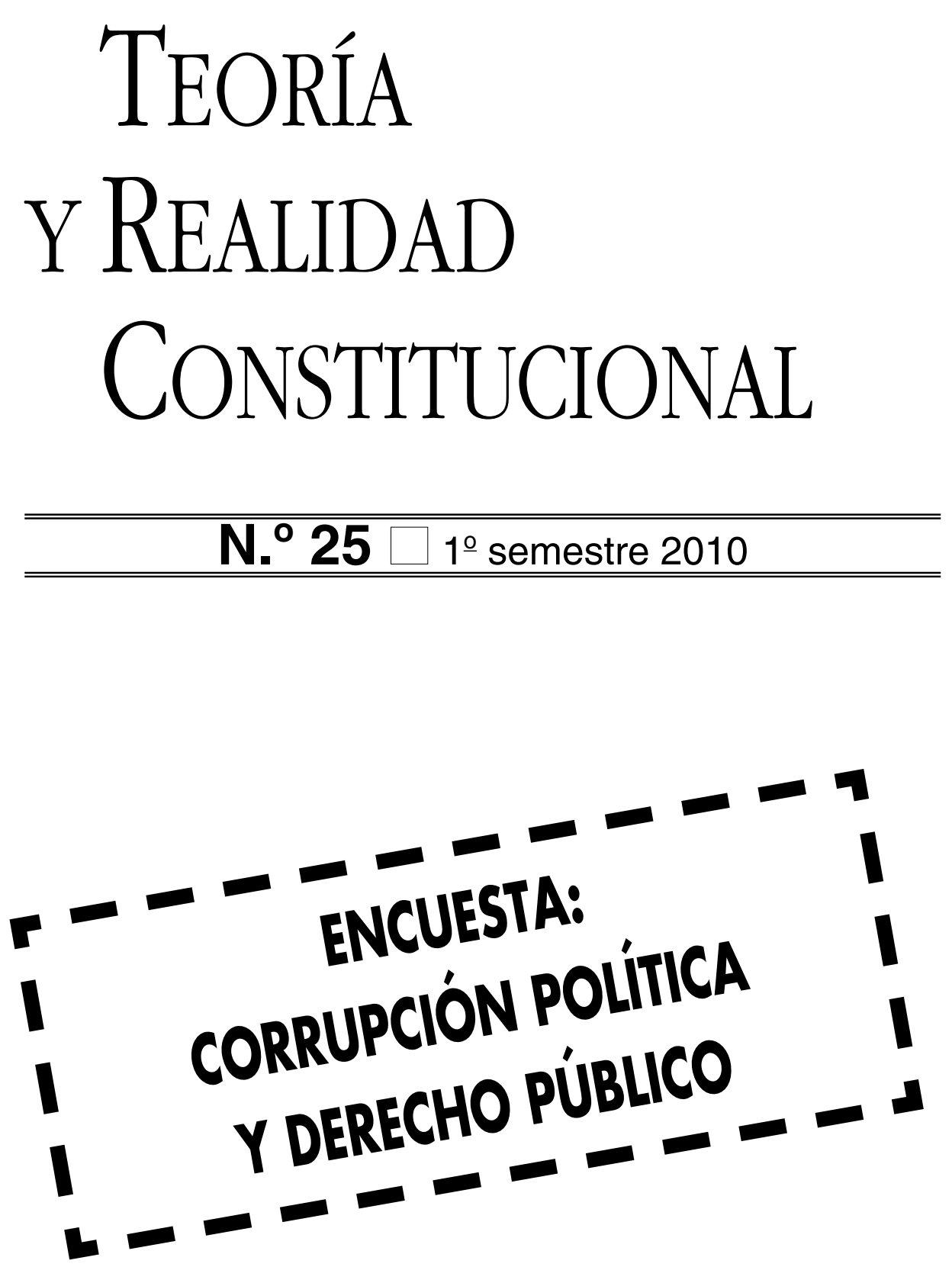


\title{
LA RATIFICACIÓN DEL TRATADO DE LISBOA EN LA REPÚBLICA CHECA
}

\author{
JOSÉ ANGEL CAMISÓN \\ Profesor de Derecho Constitucional \\ Universidad de Extremadura
}

\section{SUMARIO}

I. Introducción.

II. El proceso de ratificación del Tratado de Lisboa en la República Checa.

III. La Sentencia del Tribunal Constitucional de 26 de noviembre de 2008 sobre el Tratado de Lisboa.

IV. La Sentencia del Tribunal Constitucional de 3 de noviembre de 2009 sobre el Tratado de Lisboa.

V. El Consejo Europeo de Bruselas de 29 y 30 de noviembre de 2009.

VI. Conclusiones.

\section{INTRODUCCIÓN}

De las cenizas del fracaso del proceso de ratificación del Tratado por el que se establecía una Constitución para Europa surgió, como se sabe, ${ }^{1}$ el Tratado de Lisboa, trasunto de la malograda Constitución Europea, ${ }^{2}$ que ha

1 Vid. Punto I. Proceso de Reforma del Tratado en las Conclusiones de la Presidencia del Consejo Europeo celebrado en Bruselas el 21 y 22 de junio de 2007.

2 Téngase en cuenta que dicho Tratado no era en realidad una verdadera constitución, tal y como este concepto es entendido por la doctrina del Derecho Constitucional. MAILLO, "Génesis: el método de la Convención. La cuestión de la denominación del texto" en MÉNDEZ DE VIGO, ¿Qué fue de la Constitución Europea? El Tratado de Lisboa: un camino hacia el futuro, Madrid, CEU-Fundación Rafael del Pino-European University Institute - Planeta, 2007, pág. 46: "(...) no debemos tomar el nombre de constitución en vano. Reservemos el término constitución para el dia — si llega - en que se forme un verdadero poder constituyente y el resultado de su trabajo se aprobado directamente por los ciudadanos y los Estados que lo forman". 
adoptado la engañosa fórmula de Tratado de reforma abandonando, además, cualquier indicio de constitución. ${ }^{3}$ Dicho Tratado, que recoge en un noventa por ciento los contenidos ya previstos en el Tratado Constitucional, ${ }^{4}$ también ha sufrido de parecidos males a los que padeció su antecesor "non nato", 5 pues su proceso de ratificación tampoco ha estado privado de contratiempos y sobresaltos, tales como el resultado negativo del primer referéndum irlandés sobre el mismo celebrado en 2008, las precisiones realizadas por el Bundesverfassungsgericht ${ }^{6}$ alemán sobre el Tratado, que condujeron, incluso, a una necesaria reforma de la legislación de acompañamiento ${ }^{7}$ y, finalmente, las últimas reticencias del euroescéptico Presidente checo, Václav Klaus, a la hora de completar el procedimiento de su ratificación en la República Checa.

De entre todos estos impedimentos que jalonaron el proceso de ratificación del Tratado de Lisboa, hoy ya finalmente en vigor, nos proponemos desentrañar en este artículo aquellos que fueron protagonizados por la República Checa. Así, en este Estado miembro se sucedieron dos sentencias del Tribunal Constitucional relativas a la compatibilidad del Tratado con el orden

3 Vid. Punto I del Mandato de la Conferencia Intergubernamental contenido en el Anexo I a las Conclusiones a la Presidencia del Consejo Europeo de 21 y 22 de junio de 2007, pág. 15, en el que se afirma expresamente: "Se ha abandonado el concepto constitucional. Punto I.3 Proceso de Reforma del Tratado de las Conclusiones de la Presidencia del Consejo Europeo celebrado en Bruselas el 21 y 22 de junio de 2007: "El TUE y el Tratado sobre el funcionamiento de la Unión no tendrán carácter constitucional. La terminología utilizada en ambos Tratados reflejará este cambio: no se utilizará el término Constitución (...)».Vid. también MARTíN Y PÉREZ DE NANCLARES, El Tratado de Lisboa, Madrid, Marcial Pons, 2008, pág. 36: "Junto a la renuncia a la transparencia y a todo intento simplificador, el más claro peaje abonado por los dieciocho Estados que ya habian ratificado el Tratado Constitucional, ha sido, si se nos permite la expresión, la "ablación" de todo atisbo constitucional en futuro tratado de reforma".

4 ALDECOA LUZÁRRAGA, La Europa que viene: el Tratado de Lisboa, Madrid, Marcial Pons, 2008, pág. 25 "El Tratado de Lisboa lleva a cabo un rescate sustantivo de la Constitución Europea, ya que recoge el 90 por 100 de las reformas y los nuevos instrumentos que incluia la Constitución. Debe también tenerse en cuenta que el Tratado Constitucional, y por ende el de Lisboa, introducen en el derecho originario muchas de las normas de derecho derivado y los principios conformados por la jurisprudencia del Tribunal de Justicia de la Unión, que llevan décadas siendo aplicados; algunos autores, e incluso el propio Tribunal Constitucional Checo reconocen que el Tratado de Lisboa no cambia nada de la concepción fundamental, vid. Punto 216 de la Sentencia sobre el Tratado de Lisboa del Tribunal Constitucional de la República Checa de 26 de noviembre de 2008.

5 En Holanda (referéndum de 1 de junio de 2005) y en Francia (referéndum de 29 de mayo de 2005) no se logró ratificar el Tratado. Sí lo hicieron, en cambio, Austria, Bélgica, Chipre, Alemania, Grecia, Hungría, Italia, Letonia, Lituania, Luxemburgo, Malta, Eslovaquia, Eslovenia y España. Vid. PIRIS, El Tratado Constitucional para Europa: un análisis jurídico, Madrid/Barcelona, Ed. Marcial Pons, 2006, págs. 46 y ss. Se puede consultar un análisis profundo y detallado de las causas y efectos de los resultados negativos en Francia y Países Bajos.

6 Sentencia del Bundesverfassungsgericht de 30 de junio de 2009 sobre la ratificación del Tratado de Lisboa.

7 CHITTI, "Am Deutschen Volke. Primera nota sobre la sentencia del Bundesverfassungsgericht de 30 de junio de 2009, sobre el Tratado de Lisboa y su aplicación en Alemania" en El Cronista del Estado Social y Democrático de Derecho, núm. 7, octubre de 2009, págs. 4 y ss. 
constitucional checo y, ${ }^{8}$ también, un último intento del Presidente de la República por frenar la ratificación, cuando ya había sido autorizada por el Parlamento y bendecida por el Tribunal Constitucional, sobre la base de unas hipotéticas reclamaciones de aquellos nacionales alemanes que al final de la Segunda Guerra Mundial fueron expulsados del otrora territorio del III Reich de los Sudetes, y que hoy se encuentra dentro de las fronteras de la República Checa. Dichas reticencias se superaron finalmente gracias al compromiso alcanzado entre el Consejo Europeo y la República Checa —o, mejor dicho, su Presidente- de excepcionar a este Estado miembro de la aplicación de la Carta Europea de Derechos Fundamentales, de modo semejante a lo que ya sucede con Polonia o Reino Unido, tan pronto como haya oportunidad de incluir a tal efecto un protocolo "ad boc" - que ya ha sido incluso redactadoanejo al TUE y al TFUE, probablemente a través de una disposición específica contenida el próximo Tratado de Adhesión de nuevos Estados miembros. ${ }^{9}$

Antes de entrar en estas cuestiones procede ofrecer al lector ciertas notas sobre la Constitución de la República Checa y su Justicia constitucional, en tanto que éstas son necesarias para contextualizar y comprender el procedimiento checo de ratificación del Tratado de Lisboa, y las Sentencias del Tribunal Constitucional de dicho Estado referidas al mismo, objeto principal de este trabajo.

\subsection{Sobre la Constitución de la República Checa y su forma DE GOBIERNO}

La actual República Checa es, como se sabe, un Estado joven nacido en 1993 del colapso y posterior división de la antigua Checoeslovaquia. ${ }^{10}$ Tres años antes, en 1990, ya se habían sentado las bases de la separación de ambos territorios. Tras la caída del telón de acero hubo un intento de mantener el Estado checoeslovaco, mediante la constitución de la República Federativa Checa y Eslovaca, establecida en virtud de la Ley Constitucional checoeslovaca 556/1990. Sin embargo, dicho intento de tratar de conservar a checos y eslovacos unidos en un solo Estado no prosperó, por eso la República Checa y Eslovaca fue definitivamente disuelta sólo dos años después de su creación, en virtud de la Ley Constitucional checoeslovaca de 25 noviembre de 1992.

8 Sentencias del Tribunal Constitucional checo $\mathrm{n}^{\circ} 19 / 08$ de 26 noviembre de 2008 y $\mathrm{n}^{\circ}$ 29/09 de 3 de noviembre de 2009. Las Sentencias pueden consultarse en inglés en la web del Tribunal Constitucional checo; http://www.usoud.cz/clanek/726.

9 Vid. Punto 2 de las Conclusiones del Consejo Europeo celebrado los días 29 y 30 de octubre de 2009.

10 BARCO SERRANO, "La separación checo-eslovaca, el ingreso en la Unión Europea y la variable nacionalista" en Cuadernos Constitucionales de la Cátedra Fadrique Furió Ceriol, núm. 28/29, 1999, págs. 143 y ss. En este artículo el autor describe el proceso de disgregación del Estado checoeslovaco en dos nuevos estados: la República Checa y Eslovaquia. También se hace referencia expresa al escenario que precedía al ingreso en la Unión Europea de ambos Estados. 
Los checos procedieron entonces, por su parte, a establecer su nuevo Estado, la República Checa, y tras un breve periodo constituyente, ${ }^{11}$ aprobaron su Constitución el 16 de diciembre de 1992, que entró finalmente en vigor el 1 de enero de $1993 .{ }^{12}$

Para poder analizar las Sentencias del Tribunal Constitucional checo sobre la compatibilidad entre la Constitución de este Estado y el Tratado de Lisboa, es preciso tener en cuenta que el "orden constitucional checo" no se encuentra en un solo texto, sino que está conformado por varias normas, tal y como dispone la propia Constitución. ${ }^{13}$ De entre esta serie de normas constitucionales dos son las principales. En primer lugar, la propia Carta Magna aprobada en 1992 y, en segundo lugar, la Carta de Derechos y Libertades Fundamentales de la República Checa, promulgada como Ley Constitucional 2/1993, el 16 de diciembre de 1992, y reconocida como parte del "orden constitucional" en virtud de los artículos 3 y 112 de la Constitución. ${ }^{14}$ A estas dos normas se suman otras leyes constitucionales; por un lado, ciertas normas heredadas de la antigua Checoeslovaquia $y,{ }^{15}$ por otro, diversas normas constitucionales aprobadas en el marco de la Constitución del 92, como la Ley Constitucional 515/2002 relativa al referéndum sobre la Adhesión de la República Checa a la Unión Europea. ${ }^{16}$

En virtud la Constitución del 92 y de todas las otras leyes de rango constitucional, la República Checa se conforma como un Estado de Derecho, soberano, unitario y democrático, fundado sobre el respeto a los derechos y libertades fundamentales del hombre y del ciudadano. ${ }^{17} \mathrm{El}$ sistema de gobierno es el de república parlamentaria, ${ }^{18}$ y el Parlamento se organiza bica-

11 VALVIDARES SUÁREZ, "Breve aproximación a la Constitución de la República Checa" en Revista Española de Derecho Constitucional, Año 23, núm. 67 de enero-abril 2003, págs. 161 y 162. La autora describe el proceso constituyente de la República Checa, que debido a su inmediatez y brevedad impidió la concreción de algunos de los institutos básicos en sede constitucional.

12 Art. 113 de la Constitución de la República Checa.

13 Art. 112 de la Constitución de la República Checa.

14 VALVIDARES SUÁREZ, "Breve aproximación a la Constitución de la República Checa" en Revista Española de Derecho Constitucional, Año 23, núm. 67 de enero-abril 2003, pág., 163. Esta Declaración, que contiene la parte dogmática de la Constitución Checa, tiene su origen en la Ley Constitucional 23/1991 que fuera aprobada por la Asamblea nacional checoeslovaca.

$15 \mathrm{El}$ art. 113.1 de la Constitución Checa hace referencia a las Leyes Constitucionales de la Asamblea nacional de la República Chechoeslovaca, a las de la Asamblea Federal del Checoeslovaquia y a las del Consejo Nacional checo por las que se definen las fronteras de la República Checa. Art. 113.2 de la Constitución Checa hace referencia a la Ley Constitucional relativa a la Federación checoeslovaca y a la Ley Constitucional 1/1990 del Consejo Nacional checo sobre los símbolos del Estado de la República Checa.

16 Estas leyes constitucionales se contienen en la Carta Magna checa como anexos, que se identifican por letras. El Anexo A, contiene la Ley Constitucional 347/1997 de 3 de diciembre, por la que se crean las Altas Unidades territoriales de autogobierno. El Anexo B se dedica al la Ley Constitucional 110/1998 de 22 de abril, sobre seguridad de la República Checa. Y el anexo C se ocupa de la ya mencionada Ley sobre el referéndum de adhesión a la Unión Europea.

17 Art. 1.1. de la Constitución de la República Checa.

18 VALVIDARES SUÁREZ, "Breve aproximación a la Constitución de la República Checa", op. cit., pág., 167 y ss. 
meralmente en una Asamblea de Diputados, con doscientos miembros elegidos por sufragio universal cada cuatro años, y un Senado - con menos poderes que la Asamblea- ${ }^{19}$ que cuenta con ochenta y un miembros, elegidos para un mandato de seis años, y que se renuevan por tercios cada dos años. ${ }^{20}$ El Gobierno, por su parte, está integrado por el Primer Ministro, el Viceprimer Ministro y el resto de Ministros, que reciben conjuntamente la investidura por parte de la Asamblea de Diputados. ${ }^{21}$

En tanto que el actual Presidente de la República, Václav Klaus, ha desempeñado un papel protagonista en el proceso de ratificación del Tratado de Lisboa en la República Checa, es preciso describir constitucionalmente esta institución y, al menos, ofrecer un esbozo de la posición política de Klaus en lo relativo a la Unión Europea.

El Presidente de la República ostenta la Jefatura del Estado, es elegido por el Parlamento cada cinco años, y goza de ciertos poderes y prerrogativas que, más allá de su carácter simbólico o de representación, pueden llegar a tener cierta trascendencia político constitucional, tales como el derecho de veto a las leyes del Parlamento, la facultad de nombrar a los miembros del Tribunal Constitucional, previo consentimiento del Senado, ${ }^{22}$ el derecho a participar en las reuniones del Gobierno y del Parlamento; ${ }^{23} \mathrm{o}$, en el caso que nos ocupa, la competencia para negociar y ratificar tratados internacionales, como los relativos a la Unión Europea — normalmente ejercida en la práctica por el Gobierno y el Parlamento-. ${ }^{24}$ Tal y como afirma la doctrina checa, desde que el conservador Václav Klaus, accediera a la Presidencia de la República, esta institución ha visto fortalecidos sus poderes y su peso político, más allá de lo que el espíritu de la Constitución checa parece establecer. ${ }^{25}$

En lo que a la Unión Europea se refiere, el Presidente Klaus se ha destacado por mantener una posición muy crítica. De esta forma ha protagonizado diversos conflictos, como el acaecido en 2003 con el Ejecutivo checo, cuando canceló la delegación que el anterior Presidente de la República, Havel, había hecho a favor del Gobierno y de ciertos Ministros para que éstos pudieran

19 El modelo bicameral checo es imperfecto en tanto que la Asamblea de Diputados tiene mayores poderes que el Senado, por ejemplo, en el ámbito legislativo, pues la Asamblea puede aprobar una Ley, incluso, con el veto de Senado. Art. 47.1 de la Constitución Checa. También le corresponde a la Asamblea la investidura del Gobierno. Art. 68 de la Constitución Checa.

20 Arts. 15 y 16 de la Constitución de la República Checa.

21 Arts. 68 y ss. de la Constitución de la República Checa.

22 Art. 84.2 de la Constitución de la República Checa.

23 Art. 64 de la Constitución de la República Checa.

24 Art. 63.1.b) de la Constitución de la República Checa.

25 KYSELA y KÜHN, "Presidential Elements in Government" en European Constitutional Law Review, n 3, 2007, págs. 102 y 103: "Instead of relying moral appels, he uses his power as a tools to force the other institutions, in particular the government, to negociate. President Klaus also perceives all Presidential powers, including the share ones, as personal and emphasises that they are exercised (or not exercised) on the basis of his will alone. Although the Czech Presidency remains within the parameters of the parliamentary model, the powers of the Czech President have definitely been strengthened during the first three years of Klaus 'mandate (...)". 
concluir diversos Tratados Internacionales. También mantuvo una agria e intensa polémica con ciertos eurodiputados que criticaron sus declaraciones antieuropeístas durante 2005, e, incluso, con el mismo Presidente de la Eurocámara a quién pidió explicaciones por estas críticas en su condición de Jefe de Estado. ${ }^{26}$ Por lo que al Tratado de Lisboa se refiere, el Presidente Klaus ha tratado por todos los medios a su alcance de bloquear su entrada en vigor. "Mister No", apodo con el que era conocido el Presidente Checo en los foros comunitarios, pudo haber convenido con el líder de los Conservadores británicos, David Cameron, intentar retrasar la ratificación hasta la primavera de 2010, en la esperanza de que una victoria electoral de los tories pudiera facilitar la celebración de una referéndum en el Reino Unido sobre la ratificación del Tratado, que habría arrojado, muy previsiblemente, unos resultados contrarios a dicha ratificación. ${ }^{27}$

\subsection{Sobre la Justicia constitucional CheCa}

También es preciso referirse aquí, aunque sea brevemente, al modelo de justicia constitucional checo, pues el Tribunal Constitucional ha sido la sede donde se han ventilado los principales conflictos jurídicos relativos a la ratificación del Tratado de Lisboa. En la República Checa existe un modelo de justicia constitucional concentrado o kelseniano. Según dispone la propia Constitución, corresponde al Tribunal Constitución la tarea de "proteger la constitucionalidad ". ${ }^{28}$ Este órgano está formado por quince magistrados, nombrados por el Presidente de la República con el consentimiento del Senado para un mandato de diez años. ${ }^{29}$

Al igual que ocurre en otros Estados con un sistema de control concentrado, sin ir más lejos en España, y, como ya preconizara el propio Kelsen, ${ }^{30}$

26 Ibid. Págs. 104 a 106.

27 Vid. noticia aparecida el 30 de septiembre de 2009 en el diario El País, "Praga deja en el aire el proyecto europeo".

28 Art. 83 de la Constitución de la República Checa. En este sentido cabe señalar la definición del "Defensor de la Constitución" que en su día ofreció KELSEN en el marco de su discusión doctrinal con SCHMITT. Vid. SCHMITT y KELSEN, La polémica Schmitt/Kelsen sobre la justicia constitucional: "El defensor de la Constitución" versus "¿Quién debe ser el defensor de la Constitución?", pág. 291: "Defensor de la Constitución significa, en el sentido originario del término, un órgano cuya función es defender la Constitución contra las violaciones. De abi que se bable también y por regla general de "una garantía".

29 Art. 84 de la Constitución de la República Checa.

30 KELSEN, La garantía jurisdiccional de la Constitución, Méjico D.F., Ed. UNAM, 2001, pág. 58: "Es igualmente importante excluir de la jurisdicción constitucional a los miembros del Parlamento o del Gobierno, puesto que son precisamente sus actos los que deben ser controlados. Es muy difícil pero sería deseable alejar de la jurisprudencia del tribunal constitucional toda influencia política. No puede negarse que las determinaciones de los especialistas podrian estar influenciadas — consciente o inconscientemente - por consideraciones políticas. Si este peligro es particularmente grande es preferible aceptar, más que una influencia oculta y por tanto incontrolable de los partidos políticos, su participación en la formación del tribunal (...)”. 
también en la República Checa se han producido ciertas interferencias "políticas" en los nombramientos de los jueces del Tribunal Constitucional. En el caso checo se ha tomado como referencia el sistema norteamericano de nombramientos ${ }^{31}$ de modo que corresponde al Presidente de la República el nombramiento de los miembros del Tribunal, previo consentimiento del Senado. ${ }^{32}$ Como anticipamos, en algunos casos dichos nombramientos han sido polémicos; de esta forma la renovación de doce de los quince magistrados que debía realizarse durante 2003, se dilató hasta diciembre de 2005. El origen de esta controversia se sitúa en la negativa del Senado a consentir en el nombramiento de varios de los candidatos a magistrados propuestos por el Presidente. Ante el veto del Senado, el Presidente Klaus optó por demorar el proceso de elección de nuevos miembros, con el consiguiente bloqueo del Tribunal. El Senado, por su parte, aprobó a principios de 2004 una resolución conminado al Presidente a acelerar el proceso de nombramiento de los magistrados, incluso se llegó proponer la posibilidad de someter al Presidente Klaus a un procedimiento de "impeachment" en tanto se le consideraba responsable del retraso en la renovación del Tribunal. Finalmente, en diciembre de 2005 se nombraba a los doce nuevos magistrados, toda vez que recibieron el consentimiento del Senado para ocupar el cargo. ${ }^{33}$ Es relevante tener en cuenta los hechos relatados, en tanto que los magistrados nombrados en 2005 han sido protagonistas en la discusión, elaboración y redacción de las sentencias del Tribunal Constitucional sobre el Tratado de Lisboa, que posteriormente serán objeto de nuestro análisis.

Las competencias del Tribunal Constitucional Checo están enumeradas en la propia Constitución, entre ellas destacan, el poder para anular las leyes y actos jurídicos individuales que sean contrarios al orden constitucional, resolver las quejas presentadas por los órganos representativos de los órganos de autogobierno de los entes territoriales, controlar la ilegalización de partidos políticos, y controlar la constitucionalidad de los Tratados internacionales que la República Checa pretenda ratificar. ${ }^{34}$

\section{EL PROCESO DE RATIFICACIÓN DEL TRATADO DE LISBOA EN LA REPÚBLICA CHECA}

El proceso de ratificación del Tratado de Lisboa en el República Checa ha sido complejo y dilatado, no debemos olvidar que ha sido el último de los veintisiete Estados miembros en ratificar el Tratado llegándose a temer, incluso, que el Presidente Klaus se negara a proceder a la ratificación, con el

31 Art. II Sección 2 de la Constitución de los Estados Unidos.

32 Art. 84.2 de la Constitución de la República Checa.

33 KYSELA y KÜHN, "Presidential Elements in Government" en European Constitutional Law Review, no 3, 2007, pág. 106.

34 Art. 87.1 de la Constitución de la República Checa. 
consiguiente agravamiento de la ya profunda crisis político institucional nacida del fallido proceso de ratificación del Tratado por el que se "establecía" una Constitución para Europa. Como se sabe, el Presidente Klaus sí ratificó finalmente el Tratado, no sin antes obtener el compromiso del Consejo Europeo de excepcionar a la República Checa de la aplicación de la Carta Europea de Derechos Fundamentales. Corresponde ahora explicar cuál es el marco jurídico constitucional checo de los Tratados de la Unión Europea y su ratificación, en tanto que ese ha sido el escenario donde se ha sustanciado el conflicto.

\subsection{El MARCO CONSTITUCIONAL RELATIVO A LA RATIFICACIÓN de los Tratados de la Unión Europea}

La Constitución de la República Checa contiene una cláusula de apertura del ordenamiento constitucional, el art. $10 \mathrm{a},{ }^{35}$ semejante a la que existe en otros Estados europeos, como por ejemplo el art. 93 de la Constitución Española, en virtud de la cual se pueden transferir a organizaciones o instituciones internacionales determinadas competencias de las Autoridades de la República Checa. El art. 10a ha sido, por tanto, la vía por la que el Estado checo ha transferido competencias soberanas al nivel comunitario desde el momento de su adhesión a la Unión Europea. ${ }^{36}$

35 Art. 10a de la Constitución de la República Checa: "1. Determinadas competencias de las autoridades de la República Checa podrán ser transferidas mediante tratado a una organización o institución internacional. 2. La ratificación de un Tratado de los del párrafo primero necesita el consentimiento del Parlamento, salvo que una ley constitucional establezca que dicha ratificación necesite aprobación obtenida en referéndum. Ver también Ley Constitucional 515/2002 de 14 de noviembre relativa al referéndum de adhesión de la República Checa a la Unión Europea y las reformas de la Constitución.

36 La transferencia de competencias soberanas de los Estados a la Unión mediante la vía de las cláusulas de apertura constitucional provocan cierta alarma en la doctrina constitucionalista, en tanto que dichas cláusulas permiten que ciertas materias dejen de estar sometidas a un verdadero control democrático constitucional. En este sentido vid. CABO MARTíN, "Constitución y reforma" en GARCÍA HERRERA (Ed.), Constitución y democracia. 25 años de Constitución democrática en España, Volumen II, Bilbao, Centro de Estudios Políticos y Constitucionales-Universidad del País Vasco, 2005, pág. 650: "A través de las normas de apertura constitucional como la del art. 93 de la C.E. se posibilita - y se ha señalado oportunamente- una relación entre el Estado y la compleja red de órganos y relaciones supranacionales (Fondo Monetario Internacional, Banco Mundial, Organización Mundial del Comercio, OTAN) de la que forma parte la Unión Europea y que configuran la estructura "imperial de dominación. De acuerdo con ello las Constituciones corren el riesgo de convertirse en la legitimación formal de decisiones tomadas fuera de su ámbito (...). Vid. también en este sentido BALAGUER CALLEJÓN, "El debate constitucional en la Unión Europea: ¿Hacia una Constitución de la Unión Europea? en GARCÍA HERRERA (Ed.), Constitución $y$ democracia. 25 años de Constitución democrática en España, Volumen II, op. cit., pág. 16: "Los Estados están transfiriendo ámbitos de poder a la Unión Europea que estaban sometidos al Derecho constitucional interno y que deben seguir sometidos a Derecho constitucional (...).. LÓPEZ CASTILLO, "Cláusula constitucional de apertura a la integración (artículo $93 \mathrm{CE}$ ): balance y perspectivas" en GARCÍA HERRERA (Ed.), Constitución y democracia. 25 años de Constitución democrática en España, Volumen II, op. cit., págs. 83-94. 
La ratificación de dichos tratados internacionales de cesión de competencias, y por ende la de los de la Unión Europea, requiere del consentimiento del Parlamento checo, o en su caso, si una Ley constitucional así lo estableciera, de la aprobación del pueblo checo mediante un referéndum. La adhesión del Estado checo a la Unión Europea se realizó previa celebración de referéndum, mientras que en el caso del Tratado de Lisboa se ha recurrido a la autorización parlamentaria. ${ }^{37}$

La autorización del Parlamento, respecto de los Tratados de la Unión Europea, requiere de la aprobación tanto en la Cámara de Diputados como en el Senado. ${ }^{38}$ La propia Constitución establece la necesidad de que dicha autorización sea aprobada por una mayoría reforzada de tres quintos de los senadores, y tres quintos de los diputados presentes. ${ }^{39}$

Según dispone la Constitución checa, la ratificación final de los Tratados de la Unión Europea corresponde al Presidente de la República, y también es competencia suya la negociación de los términos del Tratado, si bien esta tarea se puede delegar en el Gobierno o en alguno de sus miembros, algo que ocurre normalmente. ${ }^{40}$ Se deja así en manos del Presidente la realización del último de los actos por los que la República checa presta su consentimiento para obligarse internacionalmente, pues, recordemos, el Presidente es, también, el Jefe del Estado. Normalmente la ratificación del Presidente constituye una formalidad, un acto debido, toda vez que el Parlamento, en tanto que sede de la representación del pueblo checo, ha conferido su autorización. No obstante, en el caso del Presidente Klaus, dicha formalidad se ha instrumentalizado como una suerte de "derecho de veto" presidencial, pues éste manifestaba no tener voluntad de ratificar el Tratado de Lisboa hasta obtener ciertas garantías relativas a la no aplicación de la Carta de Derechos Fundamentales de la Unión Europa en la República Checa, ${ }^{41}$ demanda ésta sobre la que volveremos a tratar en el punto referido al Consejo Europeo de Bruselas celebrado los días 29 y 30 de noviembre de 2009.

37 Art. 10a.2 de la Constitución de la República Checa.

38 Art. 49 de la Constitución de la República Checa. Según dispone este artículo es necesario el consentimiento de ambas Cámaras cuando el Tratado que se pretende ratificar afecte a los derechos y obligaciones de las personas, persiga establecimiento de una alianza, de la paz o tenga otra cualquier otra naturaleza política, cuando conlleve la adhesión de la República Checa a una organización internacional, si el tratado tiene una naturaleza económica y, finalmente, si trata materias que son objeto de reserva de Ley.

39 Art. 39.4 de la Constitución de la República Checa.

40 Art. 63.1.b) de la Constitución de la República Checa.

41 Vid. noticias aparecidas el 8 de noviembre de 2009 en el diario El País, "Klaus pone más trabas a Lisboa pero Kaczynski firmará el sábado" y "Klaus pone un nuevo obstáculo al Tratado de Lisboa". 


\subsection{El control de constitucionalidad de los Tratados de la Unión EUROPEA}

El Tribunal Constitucional de la República Checa es el órgano encargado del examen previo de constitucionalidad de los Tratados de la Unión Europea en virtud de los cuales el Estado pretenda transferir competencias nacionales al nivel comunitario, al amparo de la clausula de apertura constitucional contenida en art. 10a. ${ }^{42}$ La labor del Tribunal consiste en examinar la compatibilidad del Tratado que se pretende ratificar con el "ordenamiento constitucional" checo, cuando así se lo demanden.

La regulación del procedimiento se encuentra en la Ley 182/1993, de 16 de junio de 1993, y éste comienza cuando se solicita del Tribunal su pronunciamiento por parte de alguno de los legitimados para presentar una petición al respecto. Así, están legitimadas para interponer la consulta, en primer lugar, ambas cámaras del Parlamento checo, la Cámara de los Diputados y el Senado, desde el momento en que éstas reciben el Tratado hasta el momento en el que éstas conceden la autorización para la ratificación del mismo. En segundo lugar, también están legitimados activamente cuarenta y un diputados o diecisiete senadores,${ }^{43}$ bien desde el momento en que el Parlamento da su consentimiento a la ratificación del Tratado, o bien desde que dicho consentimiento se hubiera obtenido mediante referéndum, hasta que éste es efectivamente ratificado por el Presidente de la República. Y, en tercer lugar, el Presidente de la República está igualmente legitimado para acudir ante el Tribunal Constitucional, desde que recibe el Tratado para su ratificación hasta que él mismo la lleva a cabo. ${ }^{44}$

Independientemente de cuál sea el peticionario que presenta la consulta ante el Tribunal Constitucional, ${ }^{45}$ también serán parte en proceso que se suscite ante la Corte, las Cámaras del Parlamento, el Presidente de la República, y el Gobierno. ${ }^{46}$ Este último no está legitimado para interponer la consulta ante el Tribunal, pero sí se le reconoce la facultad de participar en el proceso que, en su caso, se hubiera iniciado. ${ }^{47}$

42 Art. 87.2 de la Constitución de la República Checa: "Antes de la ratificación de un Tratado del art. 10a o del art 49, el Tribunal Constitucional tendrá potestad para pronunciarse sobre la compatibilidad de dicho Tratado con el orden constitucional. El Tratado no podrá ser ratificado antes de que el Tribunal Constitucional emita su pronunciamiento".

43 Según dispone el art. 71a.2 de la Ley del Tribunal Constitucional de la República Checa, la petición al Tribunal debe ir debidamente firmada por los cuarenta y un diputados, o los diecisiete senadores, para poder ser admitida.

44 Art. 71a de la Ley del Tribunal Constitucional de la República Checa.

45 Art. 71b de la Ley del Tribunal Constitucional de la República Checa. La petición no será admitida si se incumplen los requisitos fijados para su presentación, tampoco el Tribunal procederá a examinar la compatibilidad y el Tratado cuando se haya derogado la norma constitucional, cuya compatibilidad con la norma internacional sea puesta en duda por los legitimados.

46 Art. 71 c de la Ley del Tribunal Constitucional de la República Checa.

47 Art. 71d de la Ley del Tribunal Constitucional de la República Checa. Según indica la Ley del Tribunal Constitucional las partes en el procedimiento pueden manifestar su opinión respec- 
El Tribunal centrará su análisis en establecer si existe o no incompatibilidad entre el contenido del Tratado y la Constitución ${ }^{48}$ es decir, se pronunciará expresamente sobre si el Tratado es conforme con el orden constitucional checo. ${ }^{49}$

\subsection{La jurisprudencia del Tribunal Constitucional relativa al Derecho COMUNITARIO}

$\mathrm{Al}$ igual que otros Tribunales Constitucionales de los Estados miembros de la Unión, ${ }^{50}$ también el checo ha sido llamado a pronunciarse sobre asuntos relacionados con el Derecho comunitario; incluso podemos afirmar que su jurisprudencia sobre esta materia es relativamente extensa, si se tiene en cuenta lo breve del periodo que ha transcurrido desde la adhesión de la República Checa a la Unión Europea. Procede aquí examinar, aunque sea brevemente, la jurisprudencia del Tribunal constitucional sobre asuntos relativos a la Unión Europea. No debe olvidarse que las decisiones de los Tribunales Constitucionales nacionales en referencia a la Unión Europea, fundamentalmente las que tienen que ver con el pronunciamiento de éstos en el momento previo a la ratificación de los sucesivos Tratados comunitarios, tienen una importante dimensión constitucional nacional y europea, y se proyectan hacia el resto de Estados miembros y sus jurisdicciones constitucionales. ${ }^{51}$

Antes incluso de la adhesión, este órgano ya había venido empleando en sus trabajos el derecho comunitario como una guía interpretativa subsidiaria de la normativa checa. ${ }^{52}$ Cuatro han sido sus sentencias principales que hasta la fecha — salvedad hecha de los dos recientes pronunciamientos sobre el Tratado de Lisboa- han tratado cuestiones sobre derecho comunitario.

to a la compatibilidad o incompatibilidad entre el Tratado y el "orden constitucional" que haya sido puesta en entredicho.

48 Art. 71 d de la Ley del Tribunal Constitucional de la República Checa.

49 Art. 71e de la Ley del Tribunal Constitucional de la República Checa. Cuando el Tribunal llegue a la conclusión de que el Tratado no está en conflicto con el orden constitucional lo declarará expresamente en su sentencia. Por otra parte, si la Corte Constitucional concluye que sî existe incompatibilidad, declarará cuales son las normas constitucionales que entran en conflicto; esta declaración impediría al Estado checo proceder a la ratificación del Tratado, en tanto que esta disconformidad entre Tratado y Constitución no sea debidamente resuelta, bien modificando los términos de la norma internacional, bien estableciendo los cambios necesarios en el orden constitucional checo.

50 MARTÍNEZ SIERRA, La recepción constitucional del Derecho Comunitario, Valencia, Ed. Tirant lo Blanch, 2007. En el caso español también han existido una serie de pronunciamientos significativos por parte del Tribunal Constitucional en referencia a al Derecho comunitario.

51 En este sentido debemos tener en cuenta lo que ya indicara HÄBERLE en referencia a los Tribunales Constitucionales nacionales en tanto que actores significativos en la elaboración del Derecho constitucional común europeo. HÄBERLE, "Derecho Constitucional Común Europeo" en Revista de Estudios Políticos, núm. 79, enero-marzo 1993, págs. 24 y 25.

52 ZEMÁNEK, "The Emerging Czech Constitutional Doctrine of European Law”, en European Constitutional Law Review, n 3, pág. 419. 
En primer lugar, la Sentencia sobre las cuotas del azúcar, ${ }^{53}$ en la que se estableció que la Constitución checa no puede ser confrontada con el derecho derivado, en tanto que el monopolio sobre la interpretación y la determinación de la validez de este tipo de normas corresponde al Tribunal de Justicia de la Unión Europea. Por otra parte, el Tribunal checo indicó que la primacía del derecho de la Unión no es incondicional, pues esta no puede amenazar los fundamentos de la soberanía del Estado y los otros rasgos esenciales de la República checa como el principio democrático y la forma de Estado de Derecho. ${ }^{54}$ Finalmente, el Tribunal también hacía constar que el derecho de la Unión solo prima sobre el de la República siempre y cuando haya sido dictado dentro el marco de las competencias transferidas a la Unión, siguiendo así la doctrina establecida por el Bundesverfassungsgericht en sus conocidas Sentencias Solange I y II, y la Sentencia que trataba el Tratado de Mastrique. ${ }^{55}$

En segundo lugar, destaca el pronunciamiento del Tribunal relativo a la compatibilidad de la orden de arresto europea y el ordenamiento constitucional checo. ${ }^{56}$ En este caso, se ponía en duda que la orden europea fuera compatible con el ordenamiento constitucional checo, debido, por un lado, a la disposición que la Carta checa de derechos y libertades fundamentales contiene en su artículo 14.4 por la que se prohíbe a los ciudadanos ser expulsados de su patria $y,{ }^{57}$ por otro lado, sobre la base de que con la ejecución de la orden de arresto se ponía en entredicho la obligatoriedad de que las autoridades checas comprobaran la realización del hecho criminal motivo de la detención. Finalmente el Tribunal Constitucional determinó la compatibilidad de la orden de arresto europea con la Constitución, aplicando la doctrina de la sentencia de las cuotas del azúcar, y también argumentando que la previsión del art. 14.4 de la Carta checa estaba destinada a impedir el destierro forzoso de disidentes políticos, pero no la entrega de criminales a otros Estados miembros de la Unión Europea, que, además, son Estados que respetan los

53 Sentencia 156/2006, de 8 de marzo de 2006, del Tribunal Constitucional de la República Checa sobre las cuotas del azúcar. Esta sentencia se puede consultar traducida al inglés en la web del Tribunal Constitucional Checo http://www.usoud.cz/clanek/726

54 Vid. Punto VI.B) de la Sentencia 156/2006, de 8 de marzo de 2006, del Tribunal Constitucional de la República Checa sobre las cuotas del azúcar: "La delegación de parte de las competencias de los órganos nacionales sólo persistirá en la medida en que sea compatible con los fundamentos del Estado soberano de la República Checa, y en la medida en que no amenacen la esencia fundamental del Estado de Derecho". (la traducción es nuestra).

55 ZEMÁNEK, "The Emerging Czech Constitutional Doctrine of European Law", op. cit., págs. 424 y ss.

56 Sentencia 434/2006, de 3 de mayo de 2006, del Tribunal Constitucional de la República Checa sobre la orden de arresto europea. Esta sentencia cuenta con dos votos particulares, incluso en uno de ellos se hace referencia a la legislación española, en tanto que contiene especiales previsiones para la lucha contra el terrorismo. La sentencia se puede consultar traducida al inglés en la web del Tribunal Constitucional Checo: www.usoud.cz/clanek/726

57 Art. 14.4 de la Carta checa de derechos y libertades fundamentales: "Todos los ciudadanos son libre de entrar en el territorio de la República Checa (...). Ningún ciudadano será forzado a abandonar su tierra natal." 
derechos y libertades fundamentales. ${ }^{58}$ Así, el Tribunal también aduce que se trata de una obligación enmarcada en el principio de leal cooperación, y que en la práctica constituye un mecanismo de cooperación procesal. ${ }^{59}$

La tercera de las Sentencias trata sobre la responsabilidad del Estado checo respecto a la implementación incompleta de cierta normativa comunitaria derivada de una directiva sobre fijación de precios de los medicamentos. ${ }^{60} \mathrm{Y}$ en la cuarta sentencia relevante, dictada en el marco de una cuestión de constitucionalidad — relativa a la aplicación de una normativa sobre regulación de las telecomunicaciones que podría ser contraria a la Carta checa de derechos y libertades - ${ }^{61}$ el Tribunal Constitucional reafirmó la primacía de la normativa comunitaria. ${ }^{62}$

\section{LA SENTENCIA DEL TRIBUNAL CONSTITUCIONAL DE 26 DE NOVIEMBRE DE 2008 SOBRE EL TRATADO DE LISBOA}

El origen de esta decisión se sitúa en la petición que el Senado de la República Checa presentó ante el Tribunal Constitucional para que éste se pronunciara sobre la compatibilidad del Tratado de Lisboa con el "ordenamiento constitucional" checo. Como ya hemos explicado antes, al Congreso y al Senado les corresponde autorizar la ratificación de los Tratados por los cuales la República checa transfiere competencias a la Unión Europea. Así en el marco del análisis que el Senado realizó, cuando el Tratado le fue presentado para que otorgara su consentimiento a la ratificación, se suscitaron ciertas dudas sobre su constitucionalidad. La Sentencia respecto a esta petición fue dictada el 26 de noviembre de 2008, pero no iba a ser la única que dictara el Tribunal sobre el Tratado de Lisboa, pues también se dicto otra nueva Sentencia relativa al mismo Tratado el 3 de noviembre de 2009. Debemos entender que ambos pronunciamientos forman parte de un mismo proceso de control de

58 Vid. Punto 86 de la Sentencia 434/2006, de 3 de mayo de 2006, del Tribunal Constitucional de la República Checa sobre la orden de arresto europea: "Es siempre necesario recordar que el hecho de que todos los Estados miembros de la UE son también firmantes de la Convención Europea para la protección de los derechos bumanos y las libertades fundamentales. De acuerdo con esto, un ciudadano no puede verse significativamente afectado en sus derechos a causa del becho de que su causa criminal se decida en otro Estado miembro de la Unión, en tanto que ese Estado miembro está sujeto al estándar de protección que es equivalente al estándar requerido en la República Checa".

59 ZEMÁNEK, "The Emerging Czech Constitutional Doctrine of European Law", op. cit., págs. 427 y ss.

60 Sentencia 35/2005, de 16 de enero de 2007, sobre los precios de los medicamentos.

61 Art. 95.2 de la Constitución de la República Checa: "Si un tribunal llega a la conclusión de que una ley que deba ser aplicada para la resolución de un caso está en conflicto con la Constitución, remitirá el asunto al Tribunal Constitucional"

62 Sentencia 12/2008, de 2 de diciembre de 2008, sobre primacía de las normas comunitarias. Al igual que las anteriores sentencias indicadas, también ésta se puede consultar traducida al inglés en la web del Tribunal Constitucional Checo: www.usoud.cz/clanek/726 
constitucionalidad, en tanto que ambos dictámenes se refieren al Tratado de Lisboa y su compatibilidad con el ordenamiento constitucional checo. Pasamos ahora a analizar la Sentencia de 26 de noviembre de 2008, en la que se revisó la constitucionalidad de nueve artículos concretos del Tratado de la Unión Europea y del Tratado de Funcionamiento de la Unión Europea, en su redacción dada por el Tratado de Lisboa.

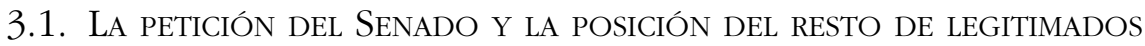

El Senado checo solicitó del Tribunal Constitucional un pronunciamiento expreso sobre la compatibilidad de ciertas disposiciones del Tratado de Lisboa con el ordenamiento constitucional checo. En la práctica, y toda vez que el Tratado de Lisboa sólo contiene enmiendas a los Tratados vigentes, dada su naturaleza de Tratado de reforma, el Senado optó por indicar qué artículos del Tratado de la Unión Europea, y del Tratado sobre el Funcionamiento de la Unión Europea, en su redacción dada por el Tratado de Lisboa, le suscitaban dudas sobre su constitucionalidad. ${ }^{63}$

El Senado argüía, en primer lugar, que las reformas introducidas por Lisboa constituían un cambio en la estructura esencial de la República Checa como Estado democrático, soberano y unitario, al afectar a contenidos constitucionales protegidos por la cláusula de intangibilidad del art. 9.2 de la Constitución Checa. ${ }^{64}$ Así, el Senado indicaba en su petición que la lista de competencias recogida en el art. 4 del TFUE es un rasgo típico de los Estados federales; además, en dicho listado de competencias, sobre todo en el caso de las competencias compartidas, no existe una clara delimitación de las competencias efectivamente transferidas a la Unión. Dicha indeterminación era, a juicio del Senado, incompatible con el art. 10a de la Constitución, en tanto que éste indica que las competencias a transferir deben estar perfectamente delimitadas. Semejantes reticencias manifestaba el Senado en lo relativo a las competencias implícitas del art. 352 del TFUE, (antiguo 308 del TCE), pues consideraba de dicha disposición se convertía, con las reformas introducidas por Lisboa, en un cheque competencial en blanco sobre el que además decidiría en última instancia el Tribunal de Justicia de la Unión, en tanto que esta institución tiene el monopolio sobre la interpretación de la normativa comunitaria. ${ }^{65}$

En segundo lugar y relacionado con lo anterior, el Senado centraba sus inquietudes sobre la posibilidad de reforma simplificada de los Tratados de la

63 El Senado aprobó una resolución el 20 de septiembre de 2007 en la que manifestaba que ciertas disposiciones del Tratado de Lisboa afectaban al orden constitucional checo.

64 Art. 9 de la Constitución de la República Checa: "1. La Constitución podrá ser enmendada o completada sólo mediante ley constitucional. 2. Cualquier cambio en los elementos básicos del Estado democrático gobernado por el imperio de la Ley no esta permitido".

65 Vid. puntos 1 a 5 de la Sentencia de 26 de noviembre de 2008. 
Unión contenida en los apartados 6 y 7 del artículo 48 del TUE; la primera permite la modificación simplificada de la tercera parte del TFUE en lo relativo a las políticas y acciones de la Unión, mientras que la segunda se refiere a las conocidas como "pasarelas" que posibilitan pasar una determinada decisión del sistema de voto por unanimidad a la mayoría cualificada, o de un procedimiento legislativo singular al procedimiento ordinario. ${ }^{66}$ Estas disposiciones no serían compatibles, según el Senado, con el art. 10a de la Constitución debido a la indeterminación que proyectan sobre las competencias transferidas y su contenido, además de ser un mecanismo unilateral de modificación que se deja en manos de la Unión y sus instituciones. Así, si del requisito de la unanimidad se pasa a la mayoría cualificada se pierde el derecho de veto, lo que sí constituye una significativa cesión de competencias y limita, además, el papel del parlamento nacional checo y su posible influencia sobre el poder ejecutivo en la arena comunitaria. ${ }^{67}$

En tercer lugar, también provocaba ciertas reticencias en el Senado la facultad reconocida a la Unión en el art. 216 del TFUE para celebrar Tratados internacionales. En virtud de esta disposición la Unión Europea puede llegar a concluir un acuerdo internacional en base a una decisión por mayoría cualificada; lo que en la práctica conlleva que dicho acuerdo, tendrá efectos en la República Checa, aún cuando no medie consentimiento del Parlamento Checo sobre el mismo, algo que viene exigido, según el Senado, por el art. 10 de la Constitución checa. ${ }^{68}$

En cuarto y último lugar, la Cámara Alta checa hizo patentes sus incertidumbres sobre la Carta Europea de Derechos Fundamentales y su aplicación, ya que las modificaciones introducidas por el Tratado de Lisboa le conferían fuerza jurídica vinculante. De esta forma el Senado indicaba que no quedaba claro en el Derecho originario qué status tendría dicha carta, en concreto se preguntaba si la disposición referida a la Carta que se introduce en el TUE conlleva protección real y efectiva de los derechos de los ciudadanos o si sólo es un instrumento de interpretación que debe guiar los objetivos de la Unión; por otra parte, también se planteaba si la Carta fortalece o resta fuerza a las autoridades checas que interpretan los catálogos naciones de derechos fundamentales en tanto que la Carta podría debilitar el estándar nacional de protección de derechos. ${ }^{69}$ Asimismo, el Senado conectaba las dudas sobre la Car-

66 En el art. 48.7 se contiene el mecanismo general de la "pasarela", si bien existen otros mecanismos específicos de pasarelas para materias concretas, por ejemplo el previsto en el art. 312.2 del Tratado sobre el funcionamiento de la Unión Europea en el caso del marco financiero plurianual.

67 Vid. punto 6 de la Sentencia del 26 de noviembre de 2008.

68 El artículo 10 de la Constitución de la República Checa indica que ambas Cámaras del Parlamento Checo deben dar su consentimiento para la ratificación de un Tratado internacional cuando este afecte los derechos y obligaciones, cuando tenga naturaleza política, cuando en virtud del mismo la República checa pase a ser miembro de una organización internacional, si el Tratado tiene una naturaleza económica general, o en caso de que el mismo afecte a materias objeto de reserva de Ley.

69 Vid. punto 10 de la Sentencia de 26 de noviembre de 2008. 
ta con el procedimiento de sanción recogido en el art. 7 del TUE, previsto para aquellos Estados que pudieran infringir de forma sistemática los valores de la Unión, pues dichos valores tampoco están claramente definidos. ${ }^{70}$

En el marco del procedimiento ante el Tribunal Constitucional se dio la oportunidad de expresar su opinión sobre la petición del Senado al Presidente de la República, a la Cámara de Diputados y al Gobierno.

Las alegaciones presentadas por el Presidente Klaus son las más extensas y profusas. En ellas se aprecia claramente las reticencias que éste tiene respecto a la Unión Europea y a la profundización en el proceso de integración que conlleva el Tratado de Lisboa. Estas alegaciones se ordenan en tres bloques. El primero de ellos se centra en la naturaleza del procedimiento que se sustancia ante el Tribunal Constitucionalidad para el examen de la compatibilidad entre Tratado de Lisboa y el "orden constitucional", y en la naturaleza del Tratado de reforma; el Presidente sostiene que un Tratado internacional no puede tener el mismo nivel que la Constitución, y que en su caso si éste fuera constitucional debiera revisarse la Constitución. Para Klaus, el Tribunal debería permitir a los legitimados, distintos del Senado, poder plantear nuevas dudas o peticiones, que se añadieran a las ya formuladas. ${ }^{71}$ El segundo bloque se centra sobre la compatibilidad del Tratado con el orden constitucional checo. El Presidente sostiene que la toma de decisiones por mayoría cualificada pone en peligro la soberanía del Estado, también indica que sólo el derecho originario de la Unión y no el derivado debía tener efecto directo. También arremete Klaus contra la Carta Europea, manifestando sus inquietudes sobre cuál debería ser la relación de ésta con la Carta checa, y si una y otra son compatibles, sugiriendo que la Carta checa debería estar en un rango superior a la europea. Por otra parte, también critica que la Unión se sitúe en una posición superior a los Estados miembros, por lo que se supera el marco fijado por el art. 10 de la Constitución, ya que la UE no es sólo una organización internacional sino un "superestado". Para el Presidente de la República la Carta no es necesaria, y con ella se pretende construir una nación europea sobre la base de la ciudadanía de la Unión. Según Klaus también se persigue este objetivo con el establecimiento de un sistema de reparto de competencias de corte federal, en el que el Presidente de la Unión podría llegar a tener voto en el Consejo Europeo. Klaus pone el acento en el hecho de que con Lisboa la naturaleza de la Unión cambia, pues la UE pasa de ser una "Organización de Estados", a una "Organización sobre los Estados". ${ }^{72}$ El tercer bloque se centra en las dudas sobre el proceso de ratificación del Tratado en la República checa y en este punto el Presidente defiende que este Tratado sólo se puede ratificar previo referéndum. ${ }^{73}$ Durante la vista pública que se celebró en el Tribunal antes de que éste dictara Sentencia, el Presidente

70 Vid. punto 11 de la Sentencia de 26 de noviembre de 2008.

71 Vid. puntos 16 y 17 de la Sentencia de 26 de noviembre de 2008.

72 Vid. puntos 19 a 26 de la Sentencia de 26 de noviembre de 2008.

73 Vid. punto 27 de la Sentencia de 26 de noviembre de 2008. 
Klaus volvió a repetir los argumentos ya expuestos y añadió a los mismos alguno más que corresponde indicar. Según el Presidente, el Tratado de Lisboa modifica "de facto" el orden constitucional checo, en tanto que afecta al núcleo intangible de la Constitución y lo modifica, poniendo en serio peligro la soberanía nacional y también el principio democrático; ya que en la Unión Europea, afirmó el Presidente, no existe un verdadero funcionamiento democrático, y Lisboa pretende, además, cortocircuitar la participación de los Parlamentos nacionales. ${ }^{74}$

El Gobierno de la República, por su parte, defendía en sus alegaciones la constitucionalidad del Tratado de Lisboa, indicando que durante las negociaciones ya se estudió la compatibilidad del mismo con la Constitución, concluyéndose que el Tratado era constitucional. La competencia sobre la competencia de la Unión corresponde al Estado, en virtud del principio de atribución de competencias, por lo que existe un límite intrínseco a la actividad de la Unión; además, las competencias cedidas se ejercen conforme a los principios de proporcionalidad y subsidiariedad. Respecto a las competencias implícitas, el Gobierno indica que éstas no son un cheque en blanco y que existen dos Declaraciones anejas al Tratado, la número 41 y número 42, que establecen ciertos límites al uso del art. 352 del TFUE (antiguo 308 del TCE). Tampoco constituyen una cesión indeterminada de competencias, a juicio del Gobierno, la posibilidad de realizar una revisión simplificada de ciertas partes del TFUE al amparo del art. 48.6 del TUE, pues ésta requiere el concurso del voto favorable de la República Checa, en tanto que es una decisión que se adopta por unanimidad, y que además puede ser bloqueada por el Parlamento nacional. Tampoco es indeterminada la transferencia de competencias al nivel comunitario porque puedan modificarse los métodos de toma de decisiones o los procedimientos de elaboración de normas, pues éstos ya se conocen de antemano. También sostiene el Gobierno que la cesión de competencias a la Unión Europea conlleva que la Unión adquiera el ejercicio tanto de los poderes internos como externos referidos a dichas competencias, lo que se traduce en que la UE podrá concluir acuerdos internacionales en el marco de dichos títulos competenciales transferidos. Finalmente el Gobierno checo indicaba respecto a la Carta Europea de Derechos fundamentales, que ésta sólo se refiere a la Unión y sus Instituciones, y a los Estados miembros cuando aplican derecho de la Unión; y que no tiene preferencia sobre la Carta nacional, constituyendo, por otra parte, un moderno instrumento de protección de los derechos de los ciudadanos frente a la Unión Europea. ${ }^{75}$

La Cámara de Diputados hizo constar en sus alegaciones que también en su seno surgieron ciertas dudas sobre el Tratado de Lisboa, por lo que se manifestó conforme con que se procediera a analizar su constitucionalidad. ${ }^{76}$

74 Vid. puntos 56 a 62 de la Sentencia de 26 de noviembre de 2008.

75 Vid. puntos 32 a 53 de la Sentencia de 26 de noviembre de 2008.

76 Vid. punto 30 de la Sentencia de 26 de noviembre de 2008. 


\subsection{El fallo del Tribunal Constitucional}

Las sentencias del Tribunal de Constitucional checo sobre la compatibilidad de los Tratados de la Unión Europea con la Constitución comienzan con el fallo, es decir, el primero de los párrafos del pronunciamiento ya contiene la decisión del Tribunal sobre la compatibilidad. En este caso el Tribunal interpretó que todos los artículos tanto del TUE como del TFUE que fueron objeto de consulta por el Senado son compatibles con el ordenamiento constitucional checo. Antes de entrar en detalle, conviene resumir aquí determinados fundamentos elaborados por el Tribunal, en tanto que son el marco jurídico en el que se insertan las decisiones concretas.

El Tribunal comienza afirmando que el Tratado de Lisboa tiene naturaleza de Tratado de reforma, semejante al de Niza o Ámsterdam. Según el Constitucional checo, en dicho Tratado se contienen cuatro tipos de provisiones distintas. En primer lugar, disposiciones basadas en la interpretación del Tribunal de Justicia de la Unión de los Tratados existentes — que no pueden ser examinadas por el Tribunal-; en segundo lugar, disposiciones modificadas similares a las que ya se contenía en el derecho originario; en tercer lugar, disposiciones derogatorias que anulan previsiones anteriores; y en cuarto lugar, disposiciones completamente nuevas, que no tiene equivalente en los Tratados anteriores - estos tres últimos tipos de disposiciones sí pueden, por el contrario, ser objeto de examen de constitucionalidad, en tanto que introducen novedades en el Derecho originario-.${ }^{77} \mathrm{El}$ Tribunal afirma además que, en la medida de lo posible, debe buscar de entre todas la interpretaciones posibles de las normas de derecho de la Unión a examinar, aquellas que sean compatibles con la Constitución, lo que no significa, sin embargo, que el orden constitucional checo se esté reformando de forma implícita. ${ }^{78}$ El Constitucional checo indica que el análisis particular de las disposiciones del Tratado discutidas debe realizarse a la luz del principio de unidad de la Constitución. ${ }^{79}$ Además también señala expresamente el Tribunal que los límites para su examen se encuentran en el núcleo esencial de la constitución, que es intangible e irreformable, constituyendo por tanto un límite material para la discrecionalidad del intérprete constitucional. ${ }^{80}$

77 Vid. puntos 81, 82 y 88 de la Sentencia de 26 de noviembre de 2008.

78 Vid. punto 85 de la Sentencia de 26 de noviembre de 2008.

79 Vid. punto 92 de la Sentencia de 26 de noviembre de 2008: "Otro argumento sustancial para la aproximación seleccionada es el principio generalmente reconocido de interpretación de la norma constitucional, normalmente llamado principio de unidad en el código constitucional o del orden constitucional. Este principio indica que es siempre necesario tomar todas la previsiones del orden constitucional e interpretarlas conjuntamente, no tomarlas fuera del contexto del conjunto de la constitución “.

80 Vid. punto 93 de la Sentencia de 26 de noviembre de 2008: "Tal y como el Tribunal Constitucional ha declarado ya, el orden constitucional de la República Checa, y sus elementos esenciales de Estado basado en la democracia y del estado de derecho — cuya reforme es inadmisible según el art. 9.2 de la Constitución - representan los criterios centrales como puntos de referencia". 
En su análisis preliminar el Tribunal Constitucional también se centra en si el art. 10a de la Constitución es la vía correcta para la ratificación del Tratado de Lisboa. Así, conviene el Tribunal que éste sí es el mecanismo constitucional idóneo, pero avisa que mediante este artículo no pueden transferirse poderes que afecten o modifiquen la identidad constitucional del Estado, o los ámbitos intangibles a la reforma constitucional contenidos en el artículo 9.2 de la Constitución checa (el Estado de derecho y la garantía de los Derechos fundamentales). ${ }^{81}$ En caso de que se traspasaran estos límites, el Tribunal podría llegar a declarar inconstitucional la normativa de la Unión. ${ }^{82}$

Veamos ahora en detalle la posición del Tribunal respecto a los artículos concretos del TUE y del TFUE que suscitaban dudas de constitucionalidad al Senado.

a) Sobre las competencias compartidas del art. 4.2 del TFUE

La lista de competencias compartidas del art. 4.2 del TFUE ${ }^{83}$ es compatible con el ordenamiento constitucional checo a juicio del Tribunal Constitucional. Según éste, la Unión no tiene la competencia sobre la decisión de sus competencias, pues esta corresponde a los Estados y se materializa en el "principio de atribución de competencias"; además, la enumeración y sistematización de las competencias de la Unión supone un avance constitucional. Por otra parte, el Tribunal recuerda que las competencias atribuidas a la Unión, en especial las compartidas, se deben ejercer observando los principios de proporcionalidad y subsidiariedad. Además, con Lisboa se ponen en marcha mecanismos que permiten una mejor verificación del cumplimiento de estos principios por parte de la Unión, como el mecanismo de alerta temprana, que permite a los Parlamentos nacionales controlar si las propuestas le-

81 Vid. puntos 97 a 110 de la Sentencia de 26 de noviembre de 2008.

82 Vid. punto 120 de la Sentencia de 26 de noviembre de 2008: "El Tribunal Constitucional de la República Checa podría (...) funcionar como ultima ratio y llegar a revisar actos de la Unión que excedieran los poderes que la República Checa ha transferido a la Unión Europea mediante el art. 10 de la Constitución". Se suma así el Constitucional checo, en cierta medida, a la "rebelión" de los Tribunales Constitucionales contra la aplicación sin restricciones del principio de la primacía del Derecho comunitario que encabezaron los Tribunales constitucionales italiano y alemán, y que ha recibido la denominación de la "teoría de los contralímites", y que ya se atisbara en la Sentencia sobre las cuotas del azúcar. Vid. en este sentido el análisis comparado de la jurisprudencia constitucional en T. GROPPI, "La "primauté" del Derecho Europeo sobre el Derecho Constitucional nacional: un punto de vista comparado", en Revista Española de Derecho Constitucional Europeo, no 5, enero-junio 2006, págs. 225 a 243. Vid. también punto 216 de la Sentencia de 26 de noviembre de 2008.

$83 \mathrm{El}$ art. 4.2. del TFUE se contiene una enumeración de los ámbitos competenciales compartidos entre la Unión Europea y los Estados miembros. En dicha lista se contienen materias como el mercado interior, el medio ambiente, el transporte, la energía o el espacio de libertad seguridad y justicia. 
gislativas de la Unión cumplen o no con dichos principios. ${ }^{84}$ Finalmente, el Tribunal indica que el listado del art. 4 del TFUE debe ser examinado a la luz de las disposiciones concretas que sobre cada ámbito competencial se contienen en el Tratado, que delimitan de forma bastante precisa cuál es la extensión real de la competencia transferida a la Unión. ${ }^{85}$

b) Sobre la cláusula de flexibilidad del art. 352 del TFUE

El Tribunal Constitucional señala que la cláusula de flexibilidad del art. 352 del TFUE ${ }^{86}$ es perfectamente compatible con el orden constitucional checo, pues se trata sólo de que la Unión pueda desarrollar ciertos poderes de acción en el marco de competencias generales que ya han sido transferidas, y que se orientan a la consecución de los objetivos de la Unión. En ningún caso puede ser utilizado el art. 352 del TFUE para modificar el Tratado. Además, su uso está limitado a unas determinadas condiciones que han quedado fijadas en las declaraciones 41 y $42^{87}$ anejas al Tratado. ${ }^{88}$

c) Sobre las "pasarelas" del art. 48.6 y .7 TUE

También considera el Tribunal que el procedimiento de revisión simplificada del art. 48.6 y las pasarelas del art. 48.7 del TUE son compatibles con la Constitución. En ambos casos se debe tener en cuenta que no son vías que permitan ampliar las competencias de la Unión, según la Corte constitucional. La reforma simplificada requiere de unanimidad, además debe ser aprobada

84 FERRER MARTÍN DE VIDALES, Los parlamentos nacionales en la Unión Europea, Madrid, Dilex, 2008.

85 Vid. puntos 125 a 140 de la Sentencia de 26 de noviembre de 2008.

86 El Art. 352 del TFUE contiene la conocida como cláusula de flexibilidad, que antes de la reforma de Lisboa se encontraba en el art. 308 del TCE, y anteriormente en el 235 del TCE. Esta disposición permite a la Unión completar ciertas lagunas competenciales sin tener que recurrir a la reforma de los Tratados. Como se sabe, el principio de atribución de competencias, que rige en la Unión, indica que ésta sólo puede ejercer aquellas competencias que expresamente le hayan sido atribuidas por los Tratados. La calusa de flexibilidad posibilita, en cambio, que la Unión pueda asumir ciertos poderes que no se hubieran previsto en los Tratados para la realización de alguno de los objetivos de la Unión contemplados en el Derecho originario.

87 Estas Declaraciones carecen de fuerza jurídica vinculante, sin embargo sí orientan la actividad de las instituciones y de la Unión, sirviendo como guías de actuación. Las Declaraciones 41 y 42 indican que el art. 352 no puede servir para modificar los Tratados ni tampoco para ampliar competencias; por otra parte, también se excluye la utilización del mismo en el ámbito de la política exterior y de seguridad común.

$88 \mathrm{Vid}$. punto 143 a 155 de la Sentencia de 26 de noviembre de 2008. El propio Tribunal Checo parafraseando la jurisprudencia del Tribunal de Justicia de la Unión, hoy contenida en la Declaración 42, indica que el art. 235 (hoy 352 TFUE) no puede se usado como base para la adopción de disposiciones cuyos efectos sean una reforma material del Tratado sin que se siga el procedimiento establecido para tal propósito. (punto 151 in fine de la Sentencia). 
por los Estados siguiendo sus normas constitucionales. ${ }^{89}$ Por su parte, las "pasarelas $" 90$ tampoco confieren más competencias y cabe, incluso, el bloqueo de los Parlamentos nacionales. ${ }^{91}$

d) Sobre la competencia de la Unión para concluir Tratados Internacionales del art. 216 del TFUE

El fallo del Tribunal reconoce que es compatible con la Constitución checa que la Unión pueda celebrar Tratados internacionales en el marco de las competencias que tiene transferidas. La Unión adquiere con Lisboa personalidad jurídica propia $\mathrm{y},{ }^{92}$ por tanto, capacidad jurídica plena para ratificar Tratados por sí misma; algo similar a lo que ya se producía en el marco de la Comunidad Europea y se recogía en el art. 300 del TCE. Tal y como reconoce el Constitucional, la trasferencia de competencias a la Unión tiene efectos tanto en el ámbito externo como en el interno, de modo que también se transfiere junto con la competencia la facultad para ratificar acuerdos internacionales en la materia. No obstante, el Tribunal reconoce la existencia de cierta ambigüedad en los términos del art. 216 TFUE,93 pero la misma no supone que éste artículo sea incompatible con el orden constitucional del Estado. ${ }^{94}$

89 Vid. Punto 160 de la Sentencia de 26 de noviembre de 2008: "El art 48.6 permite un procedimiento simplificado para adoptar cambios en la parte tres del Tratado sobre el Funcionamiento de la Unión Europea (...) que, por supuesto está sujeto a la aprobación de los Estados miembros, según sus propias normas constitucionales y no puede afectar a la atribución de nuevas competencias a la Unión."

90 Las "pasarelas" constituyen de facto mecanismos de reforma ya introducidos en los Tratados y que en el momento de ser activados permiten modificar ciertas disposiciones. Así, las pasarelas genéricas del art. 48.6. y del art. 48.7 del TUE permiten pasar de la unanimidad a la mayoría cualificada en la toma de decisiones o de un procedimiento legislativo especial al ordinario, y también existen otras pasarelas específicas que se contienen en el art. 31.3 del TUE, en el marco de la política de seguridad común, y en los arts. 81.3, 153.2, 192.2, 312.2, 333.1, y 333.2 del Tratado sobre el Funcionamiento de la Unión Europea, relativas a diversas materias.

91 Vid. Puntos 156 a 160 de la Sentencia de 26 de noviembre de 2008.

92 SOBRINO HEREDIA, “La personalidad jurídica de la Unión Europea” en MARTíN Y PÉREZ DE NANCLARES, El Tratado de Lisboa, op. cit., págs. 36 y ss. El reconocimiento de personalidad jurídica a la Unión Europea contenido en art. 47 del TUE constituye una de las novedades introducidas por el Tratado de Lisboa. Anteriormente el Derecho originario guardaba silencio a este respecto, aunque la Unión ya gozara anteriormente de facto de personalidad jurídica. La Unión Europea sucede por tanto internacionalmente a la Comunidad Europea.

93 Artículo 216 del TFUE: "1. La Unión podrá celebrar un acuerdo con uno o varios terceros países u organizaciones internacionales cuando asi lo prevean los Tratados o cuando la celebración de un acuerdo bien sea necesaria para alcanzar, en el contexto de las políticas de la Unión, alguno de los objetivos establecidos en los Tratados, bien esté prevista en un acto jurídicamente vinculante de la Unión, o bien pueda afectar a normas comunes o alterar el alcance de las mismas. 2. Los acuerdos celebrados por la Unión vincularán a las instituciones de la Unión y a los Estados miembros."

94 Vid. Punto 182 de la Sentencia de 26 de noviembre de 2008: "Debemos enfatizar que el art. 216, por su vaguedad, esta en la frontera de compatibilidad con los requisitos para la expre- 
e) Sobre la Carta Europea de Derechos Fundamentales

A juicio del Tribunal la Carta Europea de Derechos Fundamentales de la Unión Europea ${ }^{95}$ no extiende las competencias de la Unión; tampoco aprecia ningún contenido inconstitucional en la misma, siendo su contenido perfectamente compatible con el núcleo del ordenamiento constitucional y con la Carta checa de derechos y libertades. Concluye el Tribunal que la Carta Europea no constituye ningún problema y tampoco acarrea ningún peligro ni introduce ninguna duda sobre el estándar de derechos, es más, se trata de un instrumento de protección de los derechos y libertades fundamentales, y también de un límite al ejercicio del poder, por lo que es perfectamente compatible con el orden constitucional checo. ${ }^{96}$

\section{f) Sobre los valores de la Unión Europea}

Finalmente el Tribunal también se pronuncia favorablemente sobre la compatibilidad de los valores de la Unión Europea enunciados en el TUE ${ }^{97}$ con la Constitución checa y su núcleo fundamental. Dichos valores coinciden con los expresados en la Norma Fundamental de la República, por lo que ésta no debe temer ser sancionada por la Unión en virtud del art. 7 del TUE, ${ }^{98}$ pues eso indicaría que tampoco se estaría cumpliendo con la Constitución y,

sión normativa de un texto legal que surge de los principios de un Estado democrático de derecho. El Tribunal Constitucional — considerando el contenido del las competencias transferidas mediante el art. 10a de la Constitución - concluye que estas transferencias deben ser delimitadas, reconocibles y suficientemente definidas. Es precisamente la "determinabilidad" de la transferencia de poderes a una organización internacional lo que resulta problemático en el art. 216 del Tratado sobre el funcionamiento de la Unión Europea; es obvio que sus formulaciones son vagas $y$ dificiles de predecir. (...) Aunque el art. 219 del Tratado sobre el funcionamiento de la Unión Europea sea discutible, no va sin embargo tan lejos que la Corte Constitucional pudiera y debiera (...) declararlo incompatible con el orden constitucional de la República Checa)”.

95 Con la entrada en vigor del Tratado de Lisboa, la Carta de Derechos Fundamentales gozará, por fin, de fuerza jurídica vinculante. Al contrario que sucedía con el Tratado por el que se establecía una Constitución para Europa el texto de la Carta no se encuentra recogido expresamente en los Tratados, únicamente se contiene una referencia expresa a su entrada en vigor y que tendrá el mismo valor que los Tratados en el art. 6.1. del TUE.

96 Vid. Puntos 187 a 204 de la Sentencia de 26 de noviembre de 2008.

97 Art. 2 del TUE: "La Unión se fundamenta en los valores de respeto de la dignidad humana, libertad, democracia, igualdad, Estado de Derecho y respeto de los derechos bumanos, incluidos los derechos de las personas pertenecientes a minorias. Estos valores son comunes a los Estados miembros en una sociedad caracterizada por el pluralismo, la no discriminación, la tolerancia, la justicia, la solidaridad y la igualdad entre mujeres y bombres."

$98 \mathrm{El}$ art. 7 del TUE establece un procedimiento que permite sancionar a un Estado miembro de la Unión en caso de que se constate que existe por parte de éste un riesgo claro de violación de los principios en que se basa la Unión Europea. La sanción derivada de dicho procedimiento consiste en suspender al Estado miembro infractor el ejercicio de ciertos derechos, incluido el derecho a voto del representante estatal en el seno del Consejo. 
en todo caso, esa sanción constituiría para sus ciudadanos una garantía del efectivo respeto de los mismos. ${ }^{99}$

\section{LA SENTENCIA DEL TRIBUNAL CONSTITUCIONAL DE 3 DE NOVIEMBRE DE 2009 SOBRE EL TRATADO DE LISBOA}

Posteriormente, el Tribunal Constitucional recibió otra nueva petición para examinar la compatibilidad del Tratado de Lisboa con el orden constitucional checo. En este caso la petición fue presentada el 29 de septiembre de 2009 por un grupo de diecisiete Senadores, aunque parece que detrás de la misma pudiera encontrarse el propio Presidente de la República, que pretendía por esta vía dilatar aún más la ratificación del Tratado. ${ }^{100}$ Puede resultar ciertamente llamativo para el lector que el Tribunal Constitucional checo tuviera que pronunciarse de nuevo sobre el Tratado de Lisboa, no obstante la legislación checa prevé que esto pueda suceder en aras de la protección de las minorías políticas existentes. ${ }^{101}$ Como ya explicamos antes, están legitimados para interponer una consulta ante el Tribunal Constitucional sobre la compatibilidad de un Tratado internacional con la Constitución, un grupo de, al menos catorce senadores, desde el momento en que el Parlamento da su consentimiento a la ratificación del Tratado en cuestión hasta que esta se produce de forma efectiva, independientemente de que hayan podido existir otras consultas previas. ${ }^{102}$ Se trata, por tanto, de una segunda Sentencia sobre el Tratado de Lisboa, epígono de la anterior, en la que se repiten muchos de los

99 Vid. Puntos 204 a 216 de la Sentencia de 26 de noviembre de 2008. Punto 209: "Si la República observa sus propio orden constitucional, la suspensión de derechos derivada de su pertenencia a la Unión Europea no debe ser tomada en consideración. Por lo tanto, podemos concluir que la existencia de esos valores en la Unión Europea, asi como las medidas para protegerlos, son, por el contrario, pruebas que refuerzan los argumentos de que los dos sistemas, el doméstico y el de la Unión, son recíprocamente compatibles y se apoyan mutuamente en el área más importante, relativa a la esencia profunda de la ley y la justicia".

100 El consentimiento del Senado fue otorgado el 6 de mayo de 2009.

101 Vid. in extenso sobre el acceso de las minorías políticas al Tribunal Constitucional, MONTILla MARTOS, Minoría Política y Tribunal Constitucional, Madrid, Ed. Trotta, 2002, págs. 111 y ss.: "En otros ordenamientos, en lo que se ha incidido en la protección de las minorias a través del Tribunal Constitucional cuando la actuación de la mayoría tiene relevancia constitucional, existen cauces que flexibilizan la legitimación, habilitando el acceso de los pequeños grupos políticos, bien por reducción del quórum necesario para impulsar el control abstracto de normas, bien a través de otros procesos constitucionales (...)."

102 Art. 71a de la Ley del Tribunal Constitucional de la República Checa. Debe tenerse en cuenta que los pronunciamientos del Tribunal Constitucional Checo no pueden ser recurridos, por esto se entiende que los motivos de inconstitucionalidad en los que se base la reclamación presentada, respecto a un Tratado cuya compatibilidad con la constitución haya sido ya estudiada, deben ser en cierta medida novedosos. En caso de repetirse argumentos en la petición el Tribunal rechazará volver a analizar dichos argumentos, en virtud del principio de cosa juzgada. Vid. Puntos 96 a 104 de la Sentencia de 3 de noviembre de 2009 y Punto 70 de la Sentencia de de 26 de noviembre de 2008. 
argumentos y razonamientos jurídicos que ya hemos referido al analizar la Sentencia de noviembre de 2008.

Así, en la nueva Sentencia se someten a examen de la Corte Constitucional los artículos 7, 8, 9, 10.1, 13.1, 14.2, 17, 19.1, 20, 21.2h), 42, 47 y 50 del TUE, los artículos 3, 78.3, 79.1 y 83 del TFUE, y también el Tratado de Lisboa en su conjunto. Descartó el Tribunal Constitucional entrar a evaluar el Tratado de la Unión Europea en su conjunto, el análisis del art. 216 del TFUE —que ya fue objeto de pronunciamiento en la anterior Sentencia—.103 y, también el examen de la Decisión de los Jefes de Estado y Gobierno sobre el pueblo irlandés y el Tratado de Lisboa, en tanto que no la consideró como una disposición modificativa del Tratado que hiciera necesaria una nueva ratificación checa del Tratado, ni si quiera como una norma con naturaleza del tratado internacional.

Anticipamos aquí que en esta segunda Sentencia también el Tribunal declaró que sí existía compatibilidad entre el Tratado de Lisboa y los artículos concretos impugnados de los Tratados de la Unión y de su funcionamiento, y la Constitución checa.

\subsection{La PETICIÓN DEL GRUPO DE SENADORES Y LA POSICIÓN DEL RESTO DE LEGITIMADOS}

El grupo de senadores elaboró una petición en la que se buscaba cualquier tipo de resquicio jurídico que permitiera conseguir del Tribunal Constitucional una declaración de incompatibilidad o, en su defecto, un retraso en la ratificación, toda vez que las dudas fundamentales sobre la constitucionalidad del Tratado ya habían sido resueltas en la anterior Sentencia de noviembre de 2008. Por esta razón los senadores plantean una multiplicidad de cuestiones, cuestionando una larga batería de artículos e incluso los Tratados en su conjunto.

En primer lugar, los peticionarios centraron su consulta sobre el Tratado de Lisboa, argumentando que éste es incompresible en sí mismo, ${ }^{104}$ en tanto que sólo se pueden llegar a conocer verdaderamente sus efectos si previamente se hubiera adoptado una versión consolidada del TUE y del TFUE, y que para hacerlo se necesitaría una decisión unánime de los Estados miembros.

En segundo lugar, los Senadores se cuestionaban la posible existencia de incompatibilidades entre la Constitución y el Tratado de Lisboa referidas a la

103 Vid. Punto 101 de la Sentencia de 3 de noviembre de 2009.

104 En Tratado de Lisboa es, como se sabe, un Tratado de reforma que no contiene las versiones consolidadas de los Tratados sino sólo las modificaciones y enmiendas a introducir en los Tratados Constitutivos. En este sentido la alegación del grupo de senadores pretende llamar la atención sobre el hecho que el Tratado de Lisboa no es la única norma a examinar, en tanto que lo lógico sería realizar el examen sobre el texto consolidado en el que se contienen las reformas introducidas. 
redacción de determinados artículos concretos del Tratado de la Unión Europea tras la reforma. Sobre el art. 7 del TUE se argüía que su escasamente definida redacción contraviene lo dispuesto en el art. 1.1. y 2.3 de la Constitución checa, ya que si se suspenden derechos al Estado este no podrá servir plenamente a sus ciudadanos, que además serán quienes paguen en parte las consecuencias de tal suspensión de derechos. ${ }^{105}$

En relación al art. 8 del TUE, los senadores critican que no esté perfectamente definido en el Tratado qué se entiende por relaciones «especiales y cercanas" con los Estados vecinos. ${ }^{106}$ El artículo 10 del TUE se cuestiona como vía de ratificación pues, según los recurrentes, el establecimiento del principio de la democracia representativa en la Unión indica que ésta se transforma mediante el Tratado de Lisboa en un Estado. ${ }^{107}$ La cooperación reforzada se critica por los potenciales peligros que supone para la soberanía estatal; ${ }^{108}$ e igual sucede con la política exterior común y la política común de defensa europea. ${ }^{109}$ Finalmente los peticionarios piden que el Tribunal se pronuncie sobre la posibilidad de retirada de la Unión en tanto que constituye una violación de lo dispuesto en el art. 10a de la Constitución, debido al factor de indeterminación que introduce en la transferencia de competencias a la Unión. ${ }^{110}$

En tercer lugar, las críticas de los Senadores al TFUE se centran en el establecimiento de una política de inmigración común (art. 79 TFUE), pues ésta afecta a la soberanía del Estado checo, por ejemplo, cuando la Unión puede llegar a decidir incluso el número de refugiados que la República Checa debe acoger en casos de una situación de emergencia, lo que implicaría un gran número de personas desplazadas y, por tanto, un significativo impacto sobre la composición de la población estatal. ${ }^{111}$

Y, en cuarto lugar, se dirigían también al Tribunal dos nuevas peticiones al objeto de intentar retrasar en la medida de lo posible la ratificación del Tra-

105 Vid. punto 11 de la Sentencia de 3 de noviembre de 2009.

106 Vid. punto 12 de la Sentencia de 3 de noviembre de 2009

107 Vid. punto 13 de la Sentencia de 3 de noviembre de 2009. Según sostienen los peticionarios "si la democracia representativa fuera la base de la Unión Europea, esto representaria que la Unión sería en sí misma un Estado y eso contravendría el principio de que la República Checa puede transferir sólo ciertos poderes a organizaciones internacionales o instituciones, pero no la soberania en si misma".

108 Vid. punto 15 de la Sentencia de 3 de noviembre de 2009.

$109 \mathrm{Vid}$. punto 17 de la Sentencia de 3 de noviembre de 2009. La alegación de los Senadores se basa en que si la mera posibilidad que se establezca una federación europea con la República Checa como una de sus partes constituyentes contraviene el principio de que le República Checa es un Estado soberano; lo mismo puede aplicarse dirigido a la obligación de alcanzar una defensa común europea, pues sin su defensa la República Checa ya no sería un Estado Soberano.

110 Vid. puntos 6 a 18 de la Sentencia de 3 de noviembre de 2009.

111 Vid. Punto 20 de la Sentencia de 3 de noviembre de 2009. Los peticionarios argumentan que las disposiciones referidas a la inmigración son inconstitucionales pues dichas previsiones significan que la República Checa no decidiría por sí misma sobre la composición y el número de refugiados en su territorio. La Unión Europea adquiere así la competencia para participar en decisiones que tendrian un importante impacto en la composición de la población de la República Checa y sus caracteres sociales y culturales. 
tado de Lisboa por la República Checa. La primera de ellas, a la que ya hemos referido antes, perseguía que la Corte Constitucional se pronunciara sobre si la Declaración de los Jefes de Estado y de Gobierno concerniente al pueblo de Irlanda, acordada en el marco del Consejo Europeo de 18 y 19 de junio de 2009, constituía una modificación del Tratado de Lisboa que hacía necesaria una nueva autorización del Parlamento para la ratificación de dicho Tratado, en tanto que se había introducido cambios en el texto cuya ratificación se autorizara en su día por las Cámaras. ${ }^{112}$ La segunda perseguía la modificación de la legislación checa para permitir que en el mismo proceso en que se estudiaba la compatibilidad del Tratado con la Constitución se revisara también la constitucionalidad de ciertas normas estatutarias de las Cámaras del Parlamento. ${ }^{113}$

Los senadores, pretendiendo dilatar el procedimiento y clarificar sus peticiones, presentaron ante el Tribunal un suplemento a su petición el 15 de octubre de 2009, en donde se profundizaba en los argumentos ya dados a fin de que la Corte Constitucional declarara ciertos artículos del Tratado como incompatibles con la Constitución. ${ }^{114}$

Al igual que en la anterior Sentencia, también en este caso se dio la oportunidad de expresar sus opiniones a otros legitimados: Cámara de Diputados, Senado, Gobierno y Presidente de la República. La Cámara de Diputados transmitió al Tribunal Constitucional su opinión de que el Tratado era perfectamente compatible con la Constitución; ${ }^{115}$ el Senado, por su parte, también hizo constar, primero, que había conferido su consentimiento a la ratificación del Tratado de Lisboa, segundo, que ya en su día elevó sus dudas como Cámara al Tribunal y, finalmente, se hizo eco de que los senadores peticionarios ya indicaron durante los debates sus dudas sobre la constitucionalidad de dicho Acuerdo internacional. ${ }^{116}$ El Gobierno manifestó ante el Tribunal que el Tratado ya había sido examinado y que la Corte Constitucional ya había emitido su dictamen sobre el Tratado, y que éste es, por tanto, plenamente constitucional; calificó además de circunstancia excepcional que el Tratado fuera sometido a un nuevo examen, puesto que los argumentos de los peticionarios relativos a su incompatibilidad con el orden constitucional ya habían sido expresamente rechazados en la anterior Sentencia. ${ }^{117}$ Finalmente, el Gobierno ofrecía sus razonamientos detallados sobre cada uno de las disposiciones concretas del TUE y del TFUE puestas en entredicho por el grupo de

112 Vid. Punto 22 de la Sentencia de 3 de noviembre de 2009. La citada Declaración no introduce ningún cambio en el Tratado, se trata de un documento en el cual se contienen una serie de indicaciones interpretativas relativas a la aplicación del Tratado. Vid. infra «4.2. c) sobre la Decisión de los Jefes de Estado y de Gobierno concerniente al pueblo irlandés (...)”

113 Vid. Punto 23 de la Sentencia de 3 de noviembre de 2009.

114 Vid. Puntos 24 a 35 de la Sentencia de 3 de noviembre de 2009.

115 Vid. Punto 37 de la Sentencia de 3 de noviembre de 2009.

116 Vid. Punto 38 de la Sentencia de 3 de noviembre de 2009.

117 Vid. Puntos 40 de la Sentencia de 3 de noviembre de 2009. Según indicó el Gobierno "la permisibilidad de otra petición para revisar el Tratado de Lisboa debe ser una excepción". 
Senadores, argumentando a favor de su plena y satisfactoria compatibilidad con la Constitución. ${ }^{118}$

Son las opiniones del Presidente Klaus las que tienen una mayor trascendencia, en tanto que manifiestamente contrarias a la compatibilidad del Tratado con el orden constitucional. Klaus se congratula de tener una nueva oportunidad para indicar los indicios de inconstitucionalidad que considera existen en el Tratado, y lamenta que el Tribunal, a su juicio, no entrara a resolver sobre el fondo de sus posiciones en la primera Sentencia sobre el Tratado. El principal argumento del Presidente de la República pivota sobre la idea de que el Tratado de Lisboa pone en peligro la soberanía del Estado, pues transforma de facto a la Unión en un superestado europeo. ${ }^{119}$ Klaus solicita que se realice un referéndum sobre el Tratado y también pedía al Tribunal que examinara a fondo sus argumentos en contra del Tratado, dados los irreversibles efectos que la ratificación tendrá para la República Checa. Como vemos, se vuelven a utilizar los argumentos ya esgrimidos en el anterior procedimiento ante el Constitucional. ${ }^{120}$

\subsection{El fallo Del Tribunal}

El fallo del Tribunal Constitucional checo determinó que no existía ninguna incompatibilidad entre el Tratado de Lisboa y la Constitución. El Tribunal procedió a analizar uno por uno todos los argumentos presentados por el grupo de senadores. Aquí hacemos una breve recapitulación de los razonamientos del Tribunal más novedosos, pues en muchos casos éstos son repetición de los ya realizados en la Sentencia de 3 de noviembre de 2008.

a) Sobre las versiones consolidadas del TUE y del TFUE

Según el Tribunal estas versiones consolidadas a las que hacen referencia los Senadores en su petición ya existen, se ha publicado como información en el Diario de la Unión Europea; pero el examen de constitucionalidad debe centrarse en el Tratado de Lisboa que es el que entrará en vigor, y no en las versiones consolidadas de los Tratados, en tanto que éstas no son el Tratado internacional que va a ser ratificado por la República Checa. Solo pueden exa-

118 Vid. Puntos 39 a 57 de la Sentencia de 3 de noviembre de 2009.

119 Vid. Punto 59 de la Sentencia de 3 de noviembre de 2009, el Presidente Klaus plantea al Tribunal la siguiente duda, en la que manifiesta todos su temores frente al Tratado de Lisboa: "¿Continuará siendo la República Checa, después de la entrada en vigor del Tratado de Lisboa, un Estado soberano, sujeto pleno en la comunidad internacional, con capacidad para satisfacer su obligaciones nacidas del Derecho internacional?".

120 Vid. Puntos 58 a 72 de la Sentencia de 3 de noviembre de 2009. 
minarse dichos Tratados, por tanto, en lo concerniente a las reformas introducidas en ellos por el Tratado de Lisboa. ${ }^{121}$

b) Sobre la soberanía de la República Checa

Los artículos del TUE y del TFUE referidos por el grupo de Senadores como amenazas a la soberanía del Estados son conformes con el ordenamiento constitucional checo. Argumenta el Tribunal que el reconocimiento del principio de democracia representativa viene a paliar el déficit democrático de la Unión; siendo, además, perfectamente compatible con el funcionamiento democrático del Estado checo. ${ }^{122}$ Tanto el establecimiento de una política de defensa común, como de una política exterior tampoco son contrarios al orden constitucional; el hecho de que el Estado sea parte de esas políticas no resta soberanía, en tanto que se trata de acuerdos voluntariamente suscritos por la República, como sucede por ejemplo, en otro ámbito, con el Tratado de la OTAN. ${ }^{123}$ Tampoco la política común sobre inmigración persigue restar soberanía a la República Checa, sino la actuación coordinada de los Estados miembros de la UE, que busca, entre otros objetivos, combatir la inmigración ilegal, el terrorismo internacional o la trata de personas. ${ }^{124}$

La previsión de mecanismos de cooperación reforzada, por su parte, no contraviene lo dispuesto en el art. 10a de la Constitución a juicio del Tribunal, pues la decisión última de participar en las cooperaciones reforzadas que en su día se propongan, queda en manos de las autoridades constitucionales checas, fundamentalmente de las dos cámaras de su parlamento. ${ }^{125}$ También es conforme con la soberanía checa la posibilidad de abandonar la Unión, pues esta decisión corresponde al Estado que pretende salir de la Unión, eso sí, conforme a los procedimientos establecidos al efecto. ${ }^{126}$

121 Vid. Punto 108 de la Sentencia de 3 de noviembre de 2009: "(...) en relación con la petición de una revisión completa del TUE y del TFUE, el Tribunal Constitucional sólo esta autorizado a realizar dicha revisión con la extensión con la que el Tribunal de Lisboa los enmienda".

122 Vid. Puntos 134 a 140 de la Sentencia de 3 de noviembre de 2009. Punto 139:"(...) el proceso democrático de la Unión y de los niveles domésticos se complementan y son dependientes entre sí.

123 Vid. Punto 152 de la Sentencia de 3 de noviembre de 2009: "La creación de sistemas internacionales de defensa colectiva no viola en ningún modo la soberanía de los estados que comparten dichos sistemas".

124 Vid. Puntos 145 a 161 de la Sentencia de 3 de noviembre de 2009.

125 Vid. Puntos 165 y 166 de la Sentencia de 3 de noviembre de 2009.

$126 \mathrm{Vid}$. punto 14. 
c) Sobre la decisión de los Jefes de Estado y de Gobierno concerniente al pueblo irlandés adoptada en el seno del Consejo Europeo de 18 y 19 de junio de $2009^{127}$

Según los peticionarios la aprobación de esta decisión orientada a lograr la ratificación del Tratado en Irlanda, suponía introducir en el Tratado una nueva disposición, por ello requería de una nueva autorización expresa del Parlamento para que dicho Tratado pudiera ser ratificado. El Tribunal desestimó tal pretensión pues el objeto de análisis del Tribunal era el Tratado de Lisboa, y no otros actos relacionados con él, que carecen, además, de naturaleza de Tratado internacional. ${ }^{128}$

\section{EL CONSEJO EUROPEO DE BRUSELAS DE 29 Y 30 DE NOVIEMBRE DE 2009}

El Consejo Europeo de Bruselas de 29 y 30 de noviembre de 2009 constituye el último jalón relevante del complejo proceso de ratificación del Tratado de Lisboa. Como ya hemos anticipado, el Presidente Klaus se negaba a ratificar el Tratado, aún cuando dicha ratificación ya había sido autorizada por ambas Cámaras del Parlamento checo, y toda vez que el Tribunal Constitucional había declarado la compatibilidad entre dicho Tratado y el orden constitucional por dos veces.

La última de las múltiples reticencias manifestadas por Klaus se refería a la hipotética posibilidad de que los alemanes, que fueron expulsados del territorio de los "Sudetes" al final de la Segunda Guerra Mundial, o sus descendientes, pudieran solicitar algún tipo reparación por parte de la República Checa en base a la Carta Europea de Derechos Fundamentales, en tanto que el art. 17 de la Carta reconoce expresamente el derecho a indemnización en caso de expropiación, y el art. 19, por su parte, prohíbe las expulsiones co-

127 En el seno del Consejo Europeo de 18 y 19 de junio de 2009, se acordó una Decisión de los Jefes de Estado o de Gobierno de los Estados miembros, que se contiene como Anexo I de las Conclusiones de la Presidencia, en la que se tratan las preocupaciones del pueblo irlandés en referencia al Tratado de Lisboa. Como se sabe, este Estado celebró en 2008 un primer referéndum sobre la ratificación de dicho Tratado con un resultado negativo. Ante el no de los irlandeses, el Consejo Europeo adoptó en diciembre de 2008 un acuerdo con Irlanda en virtud del cual este Estado se comprometía a celebrar un nuevo referéndum y la Unión, por su parte, a aprobar una decisión relativa a las preocupaciones del pueblo irlandés (Vid. Punto I de las Conclusiones del Consejo Europeo de Diciembre de 2008). En la Decisión aprobada en junio de 2009 se contienen ciertas aclaraciones relativas a la interpretación del Tratado de Lisboa en relación con distintos ámbitos que habían sido controvertidos en Irlanda, como derecho a la vida, la institución de la familia, la educación, la fiscalidad, o la neutralidad irlandesa.

128 Vid. Puntos 176 y 177 de la Sentencia de 3 de noviembre de 2009. Punto 177: "Sólo los tratados internacionales pueden someterse al procedimiento de conformidad de los Tratados internacionales (...). El objeto de este procedimiento es el Tratado de Lisboa, no actos adoptados en conexión con él en nivel de la Unión Europea." 
lectivas. ${ }^{129}$ Por este motivo el Presidente de la República checa pretendía que se introdujera en el Tratado un precepto por el cual se excepcionará al Estado checo de la aplicación de la Carta, tal y con sucede con Polonia y Reino Unido.

Para salvar ese escoyo el Consejo Europeo acordó ceder en parte a las exigencias checas. ${ }^{130}$ Así, se convino que en el momento de celebración del próximo Tratado de Adhesión, previsiblemente el de Croacia, y de conformidad con las normas constitucionales de cada Estado miembro, se incluirá un nuevo protocolo al respecto como anexo al Tratado de la Unión y al de Funcionamiento de la Unión, por el que se extenderá a la República Checa el Protocolo $\mathrm{n}^{\circ} 30$ sobre la aplicación de la Carta de los Derechos Fundamentales, en virtud del cual ésta tendrá los mismos efectos en el Estado checo que en Reino Unido o Polonia. ${ }^{131}$

Finalmente el Presidente Klaus accedió a ratificar el Tratado de Lisboa en noviembre de 2009, si bien declaró públicamente al hacerlo que "con este Tratado, la República Checa ba dejado de ser un Estado soberano". ${ }^{132}$

\section{CONCLUSIONES}

La ratificación del Tratado de Lisboa en la República Checa ha sido un proceso complejo y dilatado. La fuerte personalidad política del Presidente Klaus y su manifiesto euroescepticismo han sido las dos variables que más han influido en el mismo, tal y como hemos podido comprobar. El Tratado de Lisboa, en tanto que un paso más en el proceso de integración europeo, supone nuevos retos para la soberanía de los Estados miembros. La transferencia de más competencias al nivel comunitario en aras de la integración política supone un nuevo reto al Derecho constitucional, que debe tutelar que el proceso de integración europeo no amenace la realización del principio democrático y la protección de los Derechos fundamentales, presupuestos irrenunciables. Es innegable que en la Unión Europea existen ciertos déficits constitucionales y democráticos que es preciso paliar, de otra forma la integración europea será tarde o temprano detenida por algún Estado miembro de manera irremediable, conduciendo a la Unión a una crisis político consti-

129 Art. 6.1 del Tratado de la Unión Europea. Como se sabe, la Carta goza de eficacia jurídica vinculante desde la entrada en vigor del Tratado de Lisboa.

130 Vid. Punto 2 de las Conclusiones del la Presidencia del Consejo Europeo de Bruselas, celebrado los días 29 y 30 de octubre de 2009.

131 Vid. Anexo 1 a las Conclusiones del la Presidencia del Consejo Europeo de Bruselas, celebrado los días 29 y 30 de octubre de 2009. Vid. in extenso sobre las especialidades de la aplicación de la Carta en Polonia y Reino Unido, PASTOR PALOMAR, "La regla inclusio unius exclusio alterius y la Carta de los Derechos Fundamentales: Polonia, el Reino Unido y los otros" en MARTÍN Y PÉREZ DE NANCLARES, El Tratado de Lisboa, op. cit., págs. 160 y ss.

132 Vid. noticia aparecida el 3 de noviembre de 2009 en el diario El País, "El Tratado de Lisboa salva el último obstáculo". 
tucional de incalculables dimensiones, pues ¿qué habría pasado si el Tribunal Constitucional checo hubiera determinado la incompatibilidad del Tratado con el orden constitucional nacional, o si, en su caso, un referéndum hubiera sido contrario a la ratificación?

Las respuestas dadas por el Tribunal Constitucional checo son similares a las ya ofrecidas anteriormente por otros Tribunales de los Estados miembros, de modo que no podemos decir que sean soluciones muy originales, aunque tampoco las dudas presentadas por los peticionarios son excesivamente novedosas.

Por otra parte, la contumacia del Presidente checo ha supuesto no sólo una crisis en el ya bastante crítico proceso de ratificación del Tratado de Lisboa, sino que ha evidenciado una profunda fractura, quizás irreconciliable, entre partidarios de la Unión Europea y euroescépticos checos, que reaparecerá en el futuro. Además, se ha comprobado la existencia de una significativa crisis político constitucional entre el Presidente de la República, por un lado, y el Gobierno y el Parlamento, por otro; en tanto que el primero, parece estar forzando sus competencias constitucionales con el consiguiente factor de tensión constitucional que esto genera en el seno del Estado.

Por último, llama poderosamente la atención el compromiso alcanzado con la República Checa para excepcionarla de la aplicación de la Carta de Derechos Fundamentales en el futuro, al igual que ya se ha hecho con Polonia y Reino Unido. En este punto cabría preguntarse qué pasará si alguno de los descendientes de los alemanes expulsados de los "Sudetes" interpusiera una demanda basada en los derechos reconocidos en la Carta mientras ésta esté vigente también para la República Checa.

TITLE: The ratification of the of the Lisbon Treaty in the Czech Republic.

ABSTRACT: This paper analyses the ratification process of the Lisbon Treaty in Czech Republic that has been the last State member to ratify the Treaty. Before the ratification, the Czech Constitutional Court has pronounced two judgments, in which has been studied if the Lisbon Treaty is consistent or not with the Czech Constitutional Order. Both of judgments state that the Treaty is perfectly consistent with the national constitutional order.

RESUMEN: El presente artículo analiza el proceso de ratificación del Tratado de Lisboa en la República Checa, que, como se sabe, ha sido en último de los Estados miembros en ratificar dicho Tratado. Antes del proceder a la ratificación el Tribunal Constitucional checo ha dictado dos Sentencias relativas a la compatibilidad del Tratado de Lisboa con el orden constitucional nacional, en ambas indica que dicho Tratado es conforme con el orden constitucional checo.

KeY WORDS: European Unión, Lisbon Treaty, Ratification, Czech Republic, Czech Constitutional Court.

Palabras Clave: Unión Europea, Tratado de Lisboa, Ratificación, República Checa, Tribunal Constitucional Checo. 